\title{
A performance musical como perspectiva das propostas teórico-analíticas de Schenker e de teóricos neoschenkerianos
}

Musical performance as a perspective of Schenker's theoretical-analytical proposal

Renata Coutinho de Barros Correia ${ }^{1}$ Universidade de São Paulo - ECA renatacoutinhobarros@gmail.com

Adriana Lopes da Cunha Moreira ${ }^{2}$ Universidade de São Paulo - ECA adrianalopes@usp.br 


\section{Resumo}

Tendo a experiência em performance como perspectiva do discurso, o artigo parte da contextualização das duas primeiras fases de Schenker com base nas publicações Die Kunst des Vortrags ("A arte da performance"), Der Tonwille ("Análise musical contextual") e Das Meisterwerke in der Musik ("As obras-primas da Música"). Discute a sua influência teórico-analítica e a concepção de performance em estudos relacionados à subárea Análise e Performance Musical, identificando vinculações entre estrutura e expressividade em análises do próprio Schenker e de teóricos neoschenkerianos. Demonstra como a percepção da interlocução entre eventos métricos e de vozes condutoras serviu como embasamento a questões de modelagem em estudos de Charles Burkhart, Steve Larson, Carl Schachter e David Beach. Este estudo não se furta de considerar os aspectos fortemente prescritivos presentes nessas propostas, mas procura estudá-los sob perspectivas de pesquisa atuais.

Palavras-chave: Análise e Performance Musical. Heinrich Schenker. Neoshenkerianismo. Gráfico em multiníveis. Parâmetros musicais.

\section{Abstract}

Performance experience is the perspective of this article's discourse, which starts from the contextualization of Schenker's first two phases, based on the publications Die Kunst des Vortrags ("The art of performance"), Der Tonwille ("Contextual Music Analysis") and Das Meisterwerke in der Musik ("The masterpieces of music"). Contextualized by a discussion about his theoretical-analytical influence and conception of performance in studies related to the Analysis and Musical Performance subarea, it identifies links between structure and expressiveness in Schenker and neo-schenkerian theorists' analyses. It demonstrates how the perception of the interlocution between metrical events and voice leading served as basis for sound modelling issues in studies elaborated by Charles Burkhart, Steve Larson, Carl Schachter and David Beach. This work does not fail to consider the strongly prescriptive aspects present in these proposals, but seeks to study them from current research perspectives.

Keywords: Musical Analysis and Performance. Heinrich Schenker. Neo-Shenkerian. Multilevel graph. Musical parameters.

\footnotetext{
1 É doutora em Musicologia (Área de concentração: Teoria e Análise Musical) e mestra em Artes (Musicologia) pela Escola de Comunicações e Artes da Universidade de São Paulo (USP). Sob a supervisão da professora Dra. Adriana Lopes da Cunha Moreira (USP/ECA) e do professor Dr. Jeffrey Swinkin (Universidade de Oklahoma/Norman) desenvolveu a tese intitulada "Análise e performance musical: perspectivas de pesquisa, influências mútuas e abordagem crítica", que trata sobre o desenvolvimento do domínio de estudos da análise e performance musical, apresentando estudo baseado na interlocução entre performer e teórico schenkeriano. Tem colaborado com publicações em eventos científicos com temas relacionados à análise musical, produção acadêmica em performance musical/práticas interpretativas e estudos em análise e performance musical. Tem se dedicado à apresentação de palestras, atividade docente e atuação como pianista colaboradora. É integrante do grupo de pesquisa TRAMA (Teoria e Análise Musical), que conta com a colaboração de pesquisadores da Escola de Comunicações e Artes (ECA) da Universidade de São Paulo.

2 É livre-docente, professora doutora associada no Departamento de Música (CMU) da Escola de Comunicações e Artes (ECA) da Universidade de São Paulo (USP, 2004-) e no Programa de Pós-Graduação em Música da ECA-USP (2010-). É coordenadora da Graduação do CMU (2017-2021) e do Grupo de Pesquisa TRAMA: Teoria e Análise Musical (ECA e CNPq, 2015-). É cocoordenadora do Laboratório de Percepção, História, Estética e Análise Musical (CMU, 2008-) e dos Encontros Internacionais de Teoria e Analise Musical, EITAM (2009-). Foi editora-chefe de publicações da ANPPOM (2011-2015), que englobam a revista OPUS (Qualis-CAPES A1), a série Pesquisa em Música no Brasil e a coordenação científica dos congressos anuais.
} 
Ao longo do século XX e neste início do século XXI, os conceitos musicais vinculados à teoria analítica proposta por Heinrich Schenker (1868-1935) têm exercido forte influência em uma ampla gama de estudos analíticos. Contudo, esses estudos não se limitam às análises que se valem da apresentação gráfica por multiníveis estruturais, com foco em relações hierárquicas entre notas, tendo como pressuposto um paradigma estruturalista.

O longo caminho que hoje encontra formas mais flexíveis e abrangentes de interação nos trabalhos de analistas como Janet Schmalfeldt (2011), Alison Hood (2014), Alexandra Pierce $(1994,2007)$ e Jeffrey Swinkin (2016) teve em sua origem possibilidades de vinculações entre estrutura e expressividade. Estas possibilidades estão latentes, ou mesmo presentes em análises do próprio Schenker, passando por propostas de neoschenkerianos como Charles Burkhart (1994), Steve Larson (1983), Carl Schachter (1991) e David Beach (1987).

Uma aprofundada compreensão dessas propostas requer desenvolvimentos prévios da capacidade de escuta interna defronte um gráfico em multiníveis e das práticas do contraponto e das relações harmônicas tonais, além de uma consolidada experiência em performance musical.

\section{O comprometimento com a performance musical e sua relação com as demais atuações de Schenker}

Em The Schenker Project (O projeto Schenker), o musicólogo Nicholas Cook (2007, p.97) ressaltou aspectos que marcaram a pluralidade do ambicioso projeto schenkeriano de reforma musical, cujo propósito era impactar a composição, o ensino musical, a atividade de edição musical, os escritos de música (produções analíticas e teóricas), a crítica, o processo de escuta de ouvintes e a performance musical. ${ }^{3}$

Mas seu compromisso com a arte da performance não ocorreu apenas no plano ideológico. Schenker foi um músico prático. Diferentes estudiosos destacaram sua atuação como pianista solista, pianista acompanhador e regente (COOK, 2007, p.18-19, 180-183; ROTHSTEIN, 1984, p.25), e o impacto de sua experiência como performer é flagrante em seus escritos. Schachter (2001, p.14) encontra especificamente na abordagem do foreground (plano frontal) das leituras analíticas de Schenker uma experiência auditiva e cinestésica advinda da performance.

3 Sua concepção de performance musical está dispersa por seus diferentes escritos. Em seu estudo sobre a Sonata em Fá menor Op. 57, de Beethoven, Schenker (2005 [1924], p.31) emprega o termo Vortrag, traduzido para performance por Robert Snarrenberg, estudioso de Schenker. Snarrenberg também foi o responsável pela tradução do artigo Der wahre Vortrag ("True Performance"), que aparece em Der Tonwille (SCHENKER, 2005 [1924], p.31). $O$ tratado inacabado de Schenker, intitulado Die Kunst des Vortrags, foi traduzido para The Art of Performance ("A arte da performance") por Irene Schreier Scott, tendo sido publicado em 2000 pela Oxford University Press. 
Schenker foi originalmente um dedicado professor de Música, tendo despendido longas horas diárias ao ensino de piano e desenvolvido uma abrangente pedagogia da performance, sobre a qual observou Cook (2007, p.21, tradução nossa):

Não se trata de aulas de piano no sentido normal do termo. A performance pianística se constituiu como parte de um programa abrangente de musicalidade, com análise e, em alguns casos, composição ocupando um lugar importante [...], e as lições poderiam ser altamente intensivas, com [...] durações prolongadas ou ocorridas em dias sucessivos. ${ }^{4}$

Essa proposta pedagógica holística de Schenker (COOK, 2013, p.34) caracterizou-se pela integração do ensino de piano com composição, teoria e análise musical, favorecendo o desenvolvimento auditivo, intelectual e de destreza manual, assim perfazendo um amplo sentido de performance musical. Ela está na base da noção de música pautada pela construção de uma performance estruturalmente orientada, que por sua vez esteve subjacente à totalidade das proposições teórico-analíticas de Schenker.

A importância da atividade analítica para a performance musical transparece em muitos de seus escritos, desde Die Kunst des Vortrags ("A arte da performance"). ${ }^{5}$ Tendo como primeiro propósito uma "performance analiticamente informada" (COOK, 2007, p.27), Schenker (2000, p.4) opôs-se à atuação de performers pouco comprometidos com linhas de condução mais estruturais, com o conhecimento das "leis de uma composição", com a "recriação" de uma composição. ${ }^{6}$

Também na atuação de Schenker como crítico reconhecemos aspectos de seu pensamento relacionado à performance. Livros como Das Meisterwerke in der Musik ("As obras-primas da Música") e Der Tonwille ("Análise musical contextual", tradução nossa) ${ }^{7}$ não se restringiram aos estudos analíticos, mas à emissão de críticas a teóricos, editores e performers de sua época (SCHENKER, 2004 [1922], p.85; 2005 [1924], p.55; 2005 [1924], p.148). Em seu estudo sobre a Sinfonia em Sol menor K 550, de Mozart, Schenker ressentiu-se do "conhecimento limitado" dos músicos de sua época, cujas performances careciam de coerência e conhecimento do todo de uma obra musical (SCHENKER, 2014b [1926], p.60).

\footnotetext{
4 Original: "This is not a matter of piano lessons in the normal sense of term. Piano performance featured as only one part of a comprehensive program of musicianship, with analysis and in some cases, composition taking a major place in it, and lessons could be highly intensive, with teaching on occasion lasting several hours or taking place on successive days [...]" (COOK, 2007, p.21).

5 Schenker dedicou-se à elaboração desse livro ao longo de vários anos, sobretudo no ano de 1911, mas não pôde completá-lo (COOK, 2007 , p.89). Anteriormente, publicou Harmonia (Harmonielehre, 1906) e o primeiro volume de Contraponto (Kontrapunkt, 2 vols, 1910 e 1922).

6 No tópico "Musical Composition and Performance", Schenker mostra seu ideal em favor de uma performance estruturalmente informada. Ele observou: "What is essential is a thorough knowledge of all laws of composition. Having enabled the composer to create, these laws, in a different way, will enable the performer to recreate the composition". "Essencial é um conhecimento profundo das leis de composição. Tendo habilitado o compositor a criar, essas leis, de uma maneira diferente, permitirão ao performer recriar a composição" (SCHENKER, 2000, p.3).
}

7 Expressão utilizada por Schenker para referir-se à "vontade da música" (GERLING; BARROS, 2020, p.40). 
A produção de edições musicais também atraiu a atenção de Schenker, que se dedicou à edição das obras para teclas de C. P. E. Bach, publicadas em 1902, e das sonatas para piano de Beethoven, publicadas em 1928 (COOK, 2007, p.19). Cook (2007, p.90) comenta a importância dessa atividade para Schenker, em decorrência de sua relevância para outras atividades musicais (composição, performance, escuta, elaboração de estudos musicais e ensino musical). Schenker também se voltou à elaboração da edição crítica da Fantasia cromática e fuga, de J. S. Bach, publicada em 1909 (ROTHSTEIN, 1984, p.4). A leitura do prefácio dessa edição revela um aspecto concernente à relação análise-performance. Schenker apresenta duras críticas à "escola de dedilhado cujos adeptos, em decorrência da ignorância ou falta de compreensão, prescrevem uma sucessão de dedilhados, inteiramente determinados por critérios externos" (SCHENKER, 1984 [1910], p.69 apud COOK, 2007, p.94). Essa afirmação é representativa da relevância que o teórico conferia ao conhecimento de conteúdo e/ou da estrutura para questões pragmáticas da performance musical.

Tanto Die Kunst des Vortrags quanto Ein Beitrag zur Ornamntik ("Uma contribuição ao estudo da ornamentação") atestam a preocupação de Schenker com a performance historicamente informada (COOK, 2007, p.90). Em diferentes estudos, Schenker incentiva o performer a consultar manuscritos autógrafos (SCHENKER, 2005 [1924], 2014b [1926]). Podemos observar nessa valorização de evidências históricas uma similaridade com ideias defendidas mais recentemente pelo Movimento da Performance Autêntica. No caso de Schenker, o incentivo à consulta dos originais pode ter servido ao propósito de reconhecer e "limpar" os acréscimos editoriais do período romântico.

Além de trazer um estudo sobre a ornamentação, Ein Beitrag zur Ornamntik deixa claro o ponto de vista de Schenker sobre expressividade musical: "Bach via em cada ornamento uma expressividade única e especial, quase como se fosse um organismo individual vivo que nunca poderia ser confundido com outro [...]. Ele considera cada ornamento não meramente um embelezamento, mas também uma expressão real e autossuficiente"8 (SCHENKER, 1976 [1903], p.51 apud COOK, 2007, p.92). Segundo Cook (2007, p.92), essa afirmativa é reveladora da "insistência hanslickiana" de que a "expressividade é uma propriedade objetiva da música". O desenvolvimento de uma "concepção objetiva" da expressividade aparece, portanto, como outra característica atrelada à proposta de performance de Schenker. ${ }^{9}$

De fato, a performance assume uma ampla dimensão na obra de Schenker, tanto na proposição da teoria como nos estudos analíticos, como bem explica Burkhart (1983, p.96, tradução nossa):

\footnotetext{
8 Original: "Bach sees in each embellishment a special and unique expressiveness, almost as if it were a living individual organism that could never be mistaken for another [...]. He regards every embellishment not merely as decoration but also as actual and self-contained expression" (SCHENKER, 1976 [1903], p.51 apud COOK, 2007, p.92).

9 Uma investigação acerca das razões deste posicionamento será analisada com maior profundidade no próximo tópico, voltado à abordagem de alguns dos estudos analíticos contidos em Der Tonwille (1921-1923/2004) e Das Meisterwerke in der Musik ("The Masterwork in Music", publicado entre os anos de 1926-1930).
} 
Enquanto a vida e a obra de Schenker envolveram a performance de muitas maneiras, desde aproximadamente 1920 ele passou a enxergá-la cada vez mais [...] em termos da teoria em multiníveis, uma ideia dominante em seu trabalho teórico do período. Em seus escritos ele abordou a questão da performance de duas [...] maneiras diferentes, dependendo se estava escrevendo um trabalho analítico ou teórico. Nos trabalhos analíticos, que são ensaios sobre peças individuais, ele frequentemente ofereceu uma análise própria com observações - geralmente bastante extensas - sobre como uma peça em questão deveria ser executada; nas obras teóricas ele estava, principalmente, apresentando uma teoria, não explicando a estrutura de uma obra particular, embora ele, bastante naturalmente, não discutisse detalhes de performance aqui, mas geralmente comentasse sobre performance em geral. Todos estes escritos atestam o forte sentimento de que sua teoria tem grande relevância para a performance. ${ }^{10}$

\section{Der Tonwille e Das Meisterwerke in der Musik: relação entre análise e performance}

Algumas características específicas dos estudos analíticos de Schenker evidenciam detalhes de seu comprometimento com a performance musical. A própria possibilidade de visualização, em um único gráfico, das linhas musicais estruturais de longo termo, em contraste com as linhas representativas dos movimentos de médios termos e dos movimentos ornamentais, revela de imediato caminhos dinâmicos para interpretações texturais e timbrísticas durante a elaboração de uma performance.

Soma-se a essa visão sinóptica da partitura uma visão hierárquica tanto entre as notas como entre estas e as diferentes camadas estruturais (MORGAN, 2014, p.18, 30). Tal hierarquia é retratada a partir da simbologia criada pelo teórico, que ressignifica caracteres comumente utilizados nas partituras para traçar uma relação hegemônica entre notas, vozes e acordes estruturais e ornamentais, lastreada em conhecidas práticas contrapontísticas, harmônicas e interpretativas. A apreensão simultânea do todo e das partes, decorrente da apresentação gráfica, é o que favorece o surgimento de insights interpretativos que muitas vezes não são percebidos de imediato ao se acessar uma obra musical, seja para tocá-la, seja para ouvi-la.

De maneira geral, as abordagens analíticas schenkerianas se caracterizam pelo emprego de procedimentos sistemáticos e rigorosos que procuram retratar diferentes técnicas de prolongamento e tipos de progressões lineares. Há uma diversidade de técnicas de prolongamento melódico descritas por Schenker em suas abordagens analíticas, como ascensão inicial, desdobramento, permuta, transferência de registro, acoplamento, superposição, aproximação superior, nota de cobertura, substituição, interrupção, ligação

10 Original: "While Schenker's life and work as a whole involved performance in many ways, from about 1920 on he came to see it more and more (though far from exclusively!) in terms of the theory of levels, the dominant idea in his theoretical work of that period. In his writings he now approached the subject of performance in two somewhat different ways, depending on whether he was writing an analytic or a theoretical work. In the analytic works, which are essays on individual pieces, he frequently followed the analysis proper with remarks - often quite extensive ones - on how the piece in question should be performed; in the theoretic works he was primarily presenting a theory, not explicating the structure of a particular piece. Therefore, he quite naturally did not discuss details of performance here, but often did comment on performance in general. All these writings testify to his strong feeling that his theory has great relevance to performance" (BURKHART, 1983, p.96). 
e paralelismo (MORGAN, 2014, p.22-29; FRAGA, 2009, p.34-52; GERLING; BARROS, 2020). O rigor do seu pensamento também é revelado por meio da organização e do detalhamento de seus gráficos, que procuram retratar diferentes camadas estruturais (planos frontal, intermediário e de fundo) de maneira hierárquica: "cada camada analítica contém o conteúdo da anterior, e dessa maneira, cada camada subsequente aumenta em detalhe"11 (MORGAN, 2014, p.29, tradução nossa).

A origem da rigorosa proposta analítica schenkeriana pode ser compreendida em relação ao contexto positivista que marcou a produção científica de diversas áreas do conhecimento. A teoria schenkeriana tem sua origem num período no qual a explanação mecânica e o método científico ocuparam o centro das preocupações de diversos intelectuais de inícios do século XX (MORGAN, 2014, p.222). Desta maneira, é possível compreender, parcialmente, algumas das razões que favoreceram a disseminação desta teoria, criada com propósito de revelar as "leis" que regem o sistema tonal. Neste sentido, esta teoria teria vindo ao encontro daqueles que ansiavam por uma visão "racional" da música, gerada por "operações precisamente definidas e aparentemente objetivas" (KERMAN, 1987, p.95).

Este contexto historicamente circunscrito tem sido alvo de duras críticas, sob argumentações a nós contemporâneas. Por considerarmos que seja merecedora de um estudo mais aprofundado, na qualidade de recurso analítico musical passível de estabelecer uma interlocução com as práticas atuais, propomos aqui um acesso à proposta da segunda fase de desenvolvimento da teoria schenkeriana, nos termos que estabeleceremos mais adiante.

Estabelecida entre 1921 e 1925, a segunda fase de desenvolvimento da teoria schenkeriana é a que corresponde ao período mais prolífero da produção do teórico e nela encontram-se inseridos o periódico Der Tonwille (1921-1924) e Das Meisterwerke in der Musik, escrito em três volumes entre 1925 e $1930^{12}$ (MORGAN, 2014, p.XVI). Ao longo das últimas décadas, vários foram os teóricos que retrataram em detalhes aspectos da teoria de Schenker (FORTE; GILBERT, 1982; COOK, 2007; CADWALLADER; GAGNÉ, 2011; MORGAN, 2014), além, é claro, dos estudiosos influenciados por esse teórico (HOOD, 2014; SWINKIN, 2016). Entretanto, poucos são os autores que se debruçaram sobre os estudos prescritivos para a performance musical desenvolvidos por Schenker (COOK, 2013, p.71).

\footnotetext{
11 Original: "[...] each analytical layer contains the contents of the previous one, so that each subsequent layer increases in detail [...]" (MORGAN, 2014, p.29).

12 Em relação às obras mencionadas, Cook (2007, p.27) observa que Schenker não empregou as concepções de Urlinie e Urzatz com o mesmo rigor e consistência do ocorrido em Der freie Satz ("Free Composition"), publicado em 1935. Segundo Cook, ambas as obras se caracterizam pelo emprego de procedimentos analíticos que tendem a ser mais "indutivos, flexíveis e mesmo improvisatórios" (COOK, 2007, p.27).
} 


\subsection{Estudos analíticos prescritivos para a performance musical}

Na segunda fase de desenvolvimento de sua teoria, Schenker defende uma visão não apenas orgânica, mas também científica da música (MORGAN, 2014, p.36). O interesse por uma abordagem científica pode ser reconhecido no subtítulo de Der Tonwille: Pamphlets in Witness of Immutable Law of Music ("Panfletos em testemunho da lei imutável da Música"). Na visão de Morgan (2014, p.136), esse subtítulo é revelador de dois princípios fundamentais para Schenker: "que a música é controlada por leis e que estas leis são eternas". Essas leis seriam demonstradas por meio da análise da estrutura das chamadas obras-primas, o que revelaria tanto o que elas têm em comum quanto o que as diferencia e as destaca das demais obras. E as obras-primas escolhidas por Schenker foram compostas por J. S. Bach, Beethoven, Brahms e Mendelssohn, além de Chopin e Schubert.

Na visão de Schenker, somente a observação de um grupo restrito de obras-primas tonais poderia revelar uma "verdade absoluta" e "eterna" sobre a música (COOK, 2007, p.7). A partir de composições canônicas, a maioria de compositores alemães, Schenker procurou formular sua teoria sobre o funcionamento de obras tonais. Segundo Cook (2007, p.11), a valorização da cultura alemã em fins do século XIX permite compreender o "ato de apropriação" dessa cultura por Schenker.

Um primeiro aspecto recorrente na maioria das análises de Schenker em Der Tonwille é a similaridade organizacional entre os diferentes estudos. Eles, em geral, são antecedidos por longas considerações analíticas ou por críticas aos músicos e teóricos da época, para depois trazer questões relacionadas à performance musical - dessa maneira, podemos notar uma clara separação entre o discurso sobre análise da estrutura e da performance musical. Tal aspecto pode ser interpretado, inicialmente, com base do projeto de reforma musical de Schenker, que visava impactar os escritos sobre música. Neste sentido, as considerações analíticas também representaram o desejo de Schenker de rebater posicionamentos sustentados por teóricos de sua época. Este interesse permite compreender, parcialmente, que as considerações puramente analíticas estejam aparentemente desvinculadas das ideias sobre performance musical.

A ordem de apresentação destas postulações e o teor das críticas sugere uma relação hierárquica entre teórico/analista e performers. Nos inícios dos tópicos dedicados a críticas aos performers, o teórico ressente-se da falta de conhecimento do conteúdo (SCHENKER, 2004 [1922], p.85; 2005 [1924], p.55; 2005 [1924], p.148), considerado uma condição imprescindível para uma "correta interpretação musical". Sobre este aspecto, Schenker afirmou: "Performers não familiarizados com o conteúdo da sonata como representado aqui, inevitavelmente se desviarão em todos os aspectos: tempo, caráter musical [Tongebung], maneira de executar, liberdade e assim por diante (SCHENKER, 2004 [1922], p.55, grifo nosso). Em sua crítica aos regentes da época, Schenker ressentiu-se pela ausência de coesão das performances de Mozart, limitadas a um virtuosismo distanciado de uma compreensão da estrutura ou do conteúdo (SCHENKER, 2014b [1926], p.60). A hegemonia da figura do teórico frente ao performer é clara: performers não familiarizados com sua proposta analítica incorreriam em erro, comprometendo suas performances ${ }^{13} \mathrm{O}$ 
performer deveria, portanto, assimilar o conteúdo revelado pelo teórico/analista.

No que concerne ao "conhecimento de conteúdo", expressão bastante recorrente nos estudos analíticos de Schenker, ele defendeu a construção e a assimilação da síntese, ou seja, a busca por uma compreensão do funcionamento das partes em relação ao todo. Logo no início de seu estudo da Sarabanda da Suíte $n$. 3, de J. S. Bach, o teórico destaca a importância do desenvolvimento de uma audição estrutural a partir de uma consciência dos eventos atuantes nas diferentes camadas estruturais. Estes eventos deveriam ser compreendidos em relação à totalidade em que ocorriam. Percebemos aqui uma relação entre o pensamento de Schenker e a Psicologia da Gestalt, cujas ideias influenciaram as teorias de músicos alemães nas décadas de 1920 e $1930^{14}$ (KERMAN, 1987). Uma possível influência destas ideias pode ser notada no início de seu estudo da peça em questão. Ele afirmou:

O olho pode seguir e contemplar as linhas de uma pintura e estrutura arquitetônica em todas as suas direções, respirações e relacionamentos; somente se o ouvido puder escutar o plano de fundo da Urzatz, e o movimento contínuo musical do plano frontal tão profundamente quanto extensivamente! Então os 24 compassos desta sarabanda poderiam ser percebidos como uma estrutura gigante, cujos muitos eventos amplos e marcantes parecem ter uma existência particular, autônoma, em que todos têm um profundo e rigoroso relacionamento com o todo. ${ }^{15}$ (SCHENKER, 2014b [1926], p.55, tradução nossa).

A parte do conhecimento de conteúdo que se dirige às prescrições à performance também revela seu interesse por um estilo de "performance estruturalmente informada", conforme tratado por Cook (1999a, p.249). Neste sentido, a relação entre análise e performance na ótica de Schenker foi considerada uma via de mão única, cujas decisões de performance deveriam se basear numa rigorosa e detalhada concepção analítica. A compreensão do "conteúdo" era tida como a base e o caminho para a construção de uma performance musical. Uma correta interpretação musical deveria estar diretamente relacionada a uma assimilação deste conteúdo pelo performer: "toda performance dever vir de dentro de uma obra; a obra precisa respirar com seus próprios pulmões - a partir das progressões lineares, notas vizinhas, notas cromáticas, modulações... Sobre

13 Paralelamente, Schenker se referiu aos instrumentistas como donos de certos saberes intrínsecos que nenhuma teoria substitui. No mencionado Die Kunst des Vortrags, observou que, sendo o piano um instrumento "imitador", o pianista deveria observar outros instrumentistas, especialmente os de cordas friccionadas, para aprender como frasear, respirar, sustentar e articular as frases musicais (SCHENKER, 2000, p.7).

14 Kerman observa que os escritos de Schenker dos anos 1920 mostram "fortes tendências tematicistas". A teoria tematicista entende que a forma de uma peça depende da "afinidade fundamental do material relativo ao tema e ao motivo" (KERMAN, 1987, p.98). Para o tematicismo, a coerência orgânica pode ser revelada por meio da observação das configurações de temas e motivos (KERMAN, 1987, p.100). Contudo, o musicólogo ressalta diferenças entre os teóricos tematicistas e a concepção do todo para Schenker. Kerman (1987, p.103) afirma: “Enquanto para os tematicistas a unidade de uma composição musical depende do modo como suas partes (sobretudo motivos e temas) se relacionam entre si, para Heinrich Schenker isso dependia do modo como as partes se integravam no todo. Quer essa teoria mereça ou não ser qualificada de 'orgânica' [...]". A busca por compreensão das partes de uma obra musical a partir da observação dos temas e motivos representa uma possível influência da Psicologia da Gestalt. No caso de Schenker, esta compreensão se deu, sobretudo, a partir da observação das vozes condutoras.

15 Original: "The eye can follow and encompass the lines of a painting or architectural structure in all their directions, breadth and relationships; if only the ear could hear the background of the Ursatz and the continuous musical motions of the foreground as profoundly and as extensively! The the twenty-four bars of this sarabande would be perceived as gigantic structure, whose many broad and striking events, while seeming to have a private, autonomous existence, all bear a profound and exacting relation to the whole" (SCHENKER, 2014b [1926], p.55). 
isto, naturalmente, não poderia haver diferentes interpretações"16 (SCHENKER apud ROTHSTEIN, 1984, p.10, tradução nossa). No interior desse conteúdo, o conhecimento da estrutura seria essencial, uma "performance correta" deveria resultar do conhecimento profundo da estrutura pelo performer (SCHENKER, 2005 [1924], p.31). Por considerar sua teoria e proposta de síntese uma verdade absoluta, afirmou sumariamente: "Uma vez que o conteúdo de uma peça é completamente compreendido, uma performance não apresentará problemas"17 (SCHENKER, 2014a [1925], p.37, tradução nossa).

A partir de seus vários estudos de caso em Der Tonwille e Das Meisterwerke in der Musik, podemos notar semelhanças no que diz respeito às preocupações analíticas. No geral, suas abordagens caracterizam-se por trazerem considerações sobre a forma musical. Esta, aliás, tem sido assunto para teóricos desde o século XVIII, culminando em diferentes correntes de pensamento, como as perspectivas conformacionais, gerativas e dialéticas (SCHMALFELDT, 2011, p.4). No caso de Schenker, sua concepção de forma aproximou-se sobretudo de uma perspectiva gerativa, mas em alguns estudos manteve uma visão conformacional. O sentido conformacional pode ser reconhecido, por exemplo, em sua abordagem analítica da Sonata em Fá menor, Op. 57, de Beethoven, na qual o teórico propõe um esquema da forma sonata do primeiro movimento (SCHENKER, 2005 [1924], p.41).

A perspectiva gerativa vincula-se às suas considerações sobre a Urzatz e a Urlinie, que aparecem na porção inicial de vários estudos analíticos. Para Schenker, a Urlinie é um fenômeno fundamental que contém as "sementes" de todas as forças que atuam numa composição tonal, obedecendo às leis da repetição e sendo comparável ao período de vida humana que tem um início e um fim. Schenker admitiu alguns entraves ao reconhecimento desta estrutura: "Enquanto motivos e melodias se agitam diante de nossos ouvidos em repetições que são facilmente perceptíveis, a Urlinie gera repetições de um tipo mais sublime e oculto em seu útero primitivo"18 (SCHENKER, 2004 [1921], p.21-22, tradução nossa). Essa comparação entre a Urlinie e o período de vida humana reflete a influência do organicismo em seu pensamento.

A comparação entre os diversos estudos que compõem Der Tonwille e Das Meisterwerke in der Musik permite notar uma diferenciação nos gráficos com vozes condutoras. O gráfico em multicamadas, como o conhecemos a partir de Free Composition (1935), não foi uma constante na obra de Schenker. Eles raramente aparecem em Der Tonwille, ocorrendo apenas a partir de Der Tonwille 5 (SCHENKER, 2004 [1923], p.202). $\mathrm{E}$, segundo Morgan, o primeiro gráfico em multiníveis aplicado à totalidade de uma obra musical aparece somente no estudo analítico da Sonata Op. 57 em Fá menor para piano, de Beethoven, em Der Tonwille 7 (MORGAN, 2014, p.141). Tal aspecto pode ser compreendido com base em Cook (2007), que chama a atenção para o emprego de

\footnotetext{
16 Original: "All performance comes from within, not from without... Performance must come from within the work; the work must breathe from its own lungs - from the linear progressions, neighboring tones, chromatic tones, modulations... About these, naturally, there cannot exist different interpretations" (SCHENKER apud ROTHSTEIN, 1984, p.10)

17 Original: "Once the content of the piece is completely understood, performance poses no problems" (SCHENKER, 2014a [1925], p.37)

18 Original: "While motives and melodies bustle about our ears in repetitions that are easily perceptible, the Urlinie begets repetitions of a concealed, most sublime sort in its primal womb [...]" (SCHENKER, 2004 [1921], p.21-22).
} 
procedimentos menos rigorosos nas análises de Der Tonwille quando comparadas com estudos posteriores de Schenker. ${ }^{19}$

Ainda no que concerne ao rigor de sua proposta analítica, podemos notar os esforços de Schenker em retratar minunciosamente o movimento das linhas. O significado do voice-leading (vozes condutoras) é apresentado como um conhecimento que deveria ser dominado pelos músicos. Esse conhecimento se constitui como a base de uma série de prescrições voltadas aos performers. No entanto, durante a construção de uma performance, ele deve necessariamente se somar a outros conhecimentos estruturais, como a abordagem motívica, a concepção da forma (em diferentes perspectivas) e a expressividade.

\subsection{Vinculação entre estrutura e expressividade}

Para Schenker a expressividade musical de um performer deveria advir de uma compreensão profunda dos eventos estruturais. ${ }^{20} \mathrm{O}$ desenvolvimento de uma concepção de performance deveria repelir critérios subjetivos, ou seja, a expressividade deveria representar uma consequência do "palpável", do verificável, a fim de aproximar-se do pensamento científico da época. Destacando a influência do pensamento científico nos estudos musicais, Kerman (1987, p.97, tradução nossa) observou: "Para Schenker, a música nunca está envolvida em metáforas de 'sentimento' ou 'expressão', mas tem a ver unicamente com as relações internas dos elementos musicais. Música é estrutura. $O$ discurso musical deve ser puramente musical". ${ }^{21}$

Como exemplos, podemos citar algumas das decisões relativas à dinâmica. Schenker procurou demonstrar como a percepção da relação entre direcionamento da linha, eventos harmônicos e métrica poderia favorecer a seleção de estratégias de dinâmica. Diante da limitação da notação musical em relação às indicações de sutilezas de dinâmica, Schenker propôs um esquema representativo de tais sutilezas (Fig. 1c). No exemplo a seguir, Schenker (2004 [1922], p.87) recomenda um decrescendo a partir do primeiro tempo do compasso 1, que por sua vez deveria ser precedido por outro decrescendo, partindo do upbeat precedente. Nas Fig. 1b e 1c do exemplo, podemos inferir uma ênfase de dinâmica no acorde de Fá menor (compasso 1) em decorrência de sua posição estrutural (acorde formado sobre a tônica). De acordo com o gráfico do plano médio (middleground), a nota Si inicia uma progressão linear de terça, localizando-se no tempo forte (compasso 1). Tais aspectos corroboraram a ênfase de dinâmica em relação

\footnotetext{
19 Não se quer aqui defender a ideia da falta de rigor analítico nesta obra, que é anterior ao livro Free Composition (1935), mas sim reconhecer que obras anteriores a esse livro (Der Tonwille 7, por exemplo) oferecem um método de análise em vias de se consolidar, em processo de formulação.

20 Schenker também ressaltou outros conhecimentos com potencial de colaborar para esta questão. No mencionado Die Kunst des Vortrags, observou que, sendo o piano um instrumento "imitador", o pianista deveria observar outros instrumentistas, especialmente os de cordas friccionadas, para aprender como frasear, respirar, sustentar e articular as frases musicais (SCHENKER, 2000, p.7).

21 Original: "Music as expounded by Schenker is never concerned with metaphors of 'feeling' or 'expression' but only with the internal relationship of musical elements. Music is structure. Musical discourse must be purely musical" (KERMAN, 1985, p.97).
} 
à nota Sol. A ênfase dada à nota Dó (compasso 4) pode ser compreendida em relação à sua posição estrutural (faz parte do acorde formado sobre a tônica de Láb Maior). A comparação entre o plano médio e a Fig. 1c permite compreender a influência da análise estrutural de Schenker em suas decisões de dinâmica.
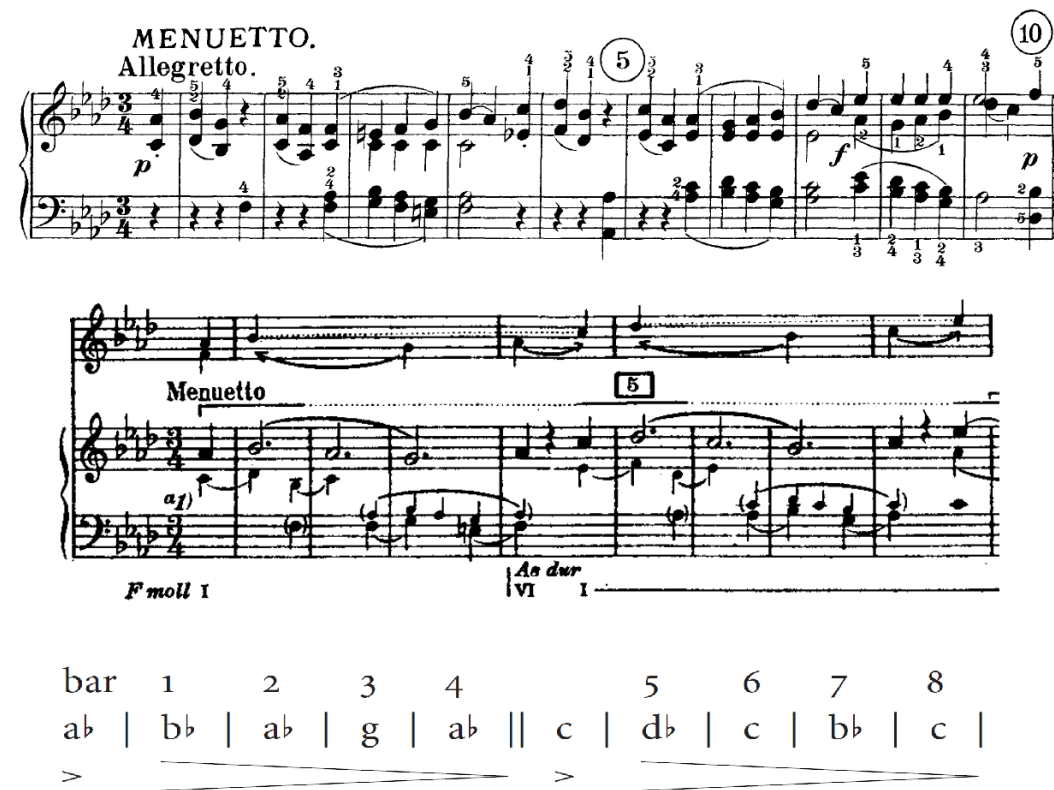

Fig. 1 - Beethoven, Sonata Op. 2 n. 1, para piano, III: Minueto (compassos 1-8) - Estratégia de modelagem de dinâmica em estudo de Schenker. Fig. 1a: Excerto dos compassos iniciais; Fig. 1b: Excerto do plano intermediário do Minueto;

Figura 1c: Gráfico representativo das nuances de dinâmica.

Fontes: Fig 1a - Beethoven (1975 [1795]); Fig. 1b e 1c - Schenker (2004 [1922], p.79-87).

O tratamento de desafios relacionados à dinâmica também foi discutido por Schenker a partir da observação da inter-relação entre forma e eventos harmônicos. Isto ocorreu em sua análise das Variações e fuga sobre um tema de Händel, Op. 24, de Brahms (Fig. 2). Schenker observou a ausência de indicações de dinâmica na Aria, que corresponde ao Tema de Händel e apresentou um esquema representativo de dinâmica, a partir da influência de sua concepção de forma (tripartida de canção) e da presença de uma cadência autêntica perfeita (compasso 8). A comparação entre seu esquema e o excerto da partitura permite notar a indicação de dinâmica decrescendo para trecho recessivo em decorrência desta cadência. A consciência da resolução com notas ornamentais (quarto tempo dos compassos 1 e 2) também aparece como fator que contribuiu para a seleção de estratégias de dinâmica, conforme indicado pelo esquema da Fig. 2b. Nele, o reconhecimento das seções $B$ (compassos 5-6) e seção $A^{\prime}$ (compassos 7-8) também serviram como recurso à seleção de estratégia de dinâmica. 

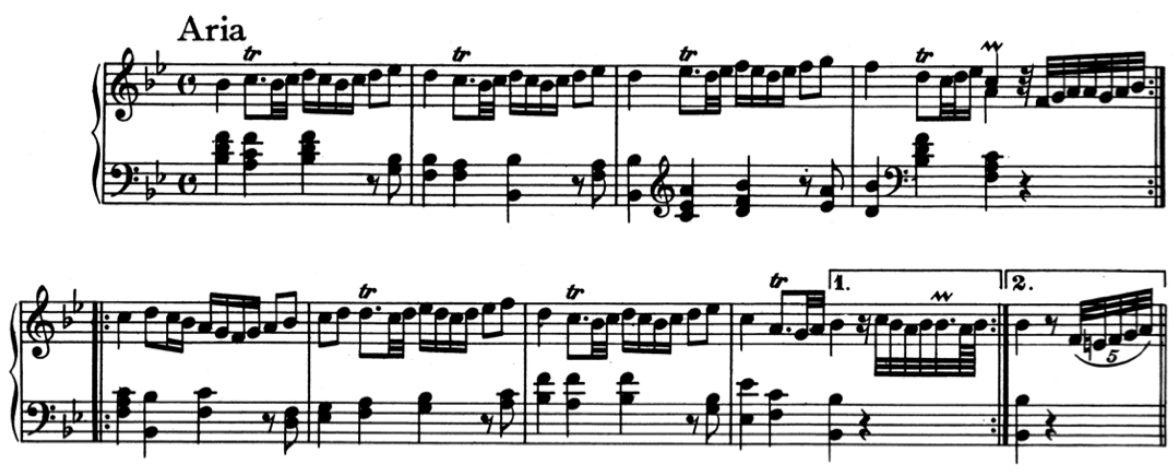

T. 1

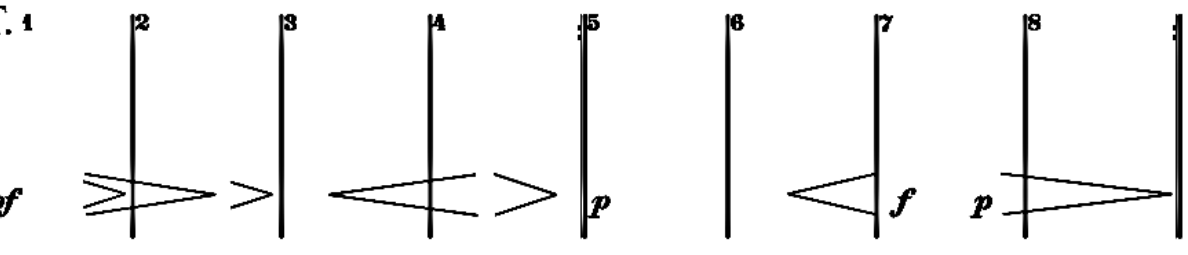

Fig. 2 - Brahms, Variações e fuga sobre um tema de Händel, Op. 24,

para piano: Ária (compassos 1-8) - Estratégia de modelagem da dinâmica em estudo de Schenker.

Fig. 2a: Excerto dos compassos iniciais; Fig. 2b: Esquema ilustrativo das sutilezas de dinâmica.

Fontes: Fig. 2a - Brahms (1927 [1862]); Fig. 2b - Schenker (2005 [1924], p.107).

Outros casos relacionados ao emprego da dinâmica também foram tratados com base na observação da inter-relação entre figuração melódica e eventos harmônicos. É recorrente nas narrativas prescritivas de Schenker a discussão sobre a relação entre dinâmica e eventos harmônicos envolvendo o emprego de apojaturas. A observação sobre o emprego de apojaturas na terceira variação do Op. 24, de Brahms (Fig. 3) serviu como recurso à seleção de estratégia de dinâmica. Schenker (2005 [1924], p.108, tradução nossa) observou: "Em decorrência do efeito de suspensão, grande peso deveria ser dado à primeira colcheia no decorrer dos primeiros tempos [...]":22
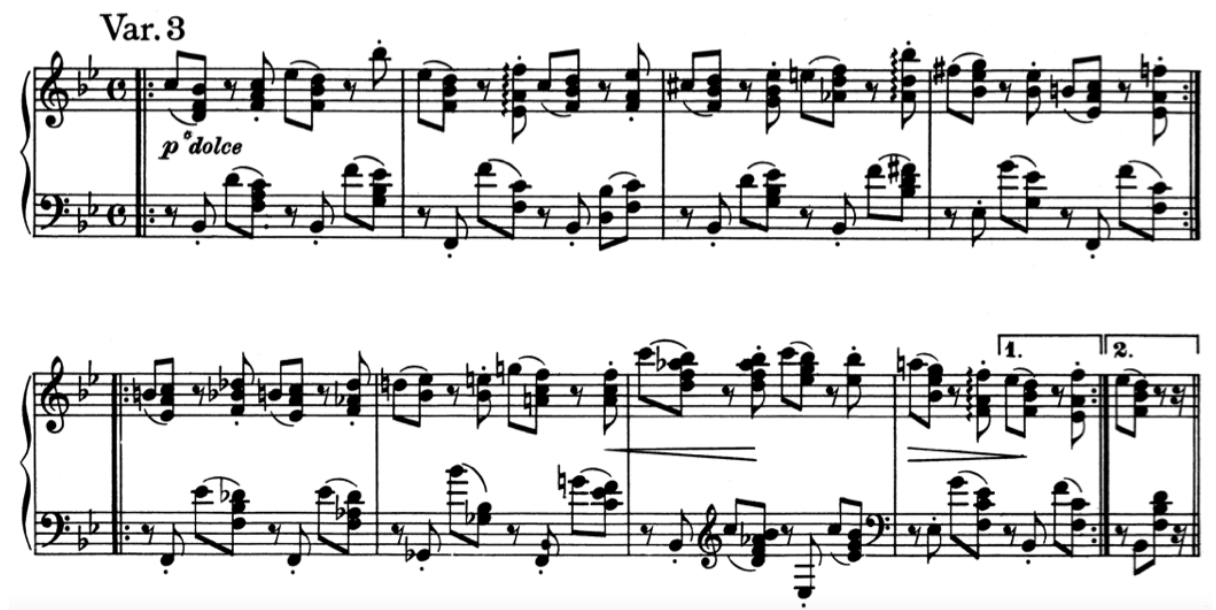

Fig. 3 - Brahms, Variações e fuga sobre um tema de Händel, Op. 24, para piano: Variação 3 (compassos 1-8) - Emprego de apojaturas. Fonte: Brahms (1927 [1862]).

22 Original: "Because of the suspension effect, greater weight should be given to the first eighth note of each beat through, even though it is always unaccompanied, than to the chord that follows in the second eighth!" (SCHENKER, 2005 [1924], p. 108). 
A leitura do estudo sobre as Variações e fuga sobre um tema de Händel Op. 24, de Brahms, também permite reconhecer outro tipo de questão pragmática de Schenker: o tratamento temporal. Como observado na Fig. 3, o trecho final da terceira variação é coincidente como uma cadência autêntica imperfeita na tonalidade de Sib maior (compasso 8). Se no estudo anterior a observação de trechos recessivos serviu de base ao tratamento da dinâmica, Schenker procura demonstrar como o reconhecimento de trecho recessivo pode servir como recurso à modelagem do tempo. Desse modo, Schenker (2005 [1924], p.108) destaca a presença do acorde formado sobre o quinto grau no segundo tempo (compasso 8 ) e prescreve um breve allargando antes da entrada do acorde formado sobre a tônica.

O tratamento temporal também é abordado em sua análise do Primeiro Movimento da Sonata em Fá menor para piano, Op. 2 n. 1, de Beethoven (Fig. 4). Em seu estudo, Schenker proporciona uma estratégia à modelagem do tempo com base na sua percepção da inter-relação entre movimento da linha e evento harmônico. O teórico propôs um allargando a partir do terceiro tempo do compasso 7 em decorrência do desvio da linha (compassos 7 e 8), da cadência suspensiva e da fermata (compasso 8). A observação do sentido ascendente da linha corroborou com a escolha interpretativa em favor de uma aceleração entre os compassos 5 a 6 (SCHENKER, 2004 [1922], p.86).
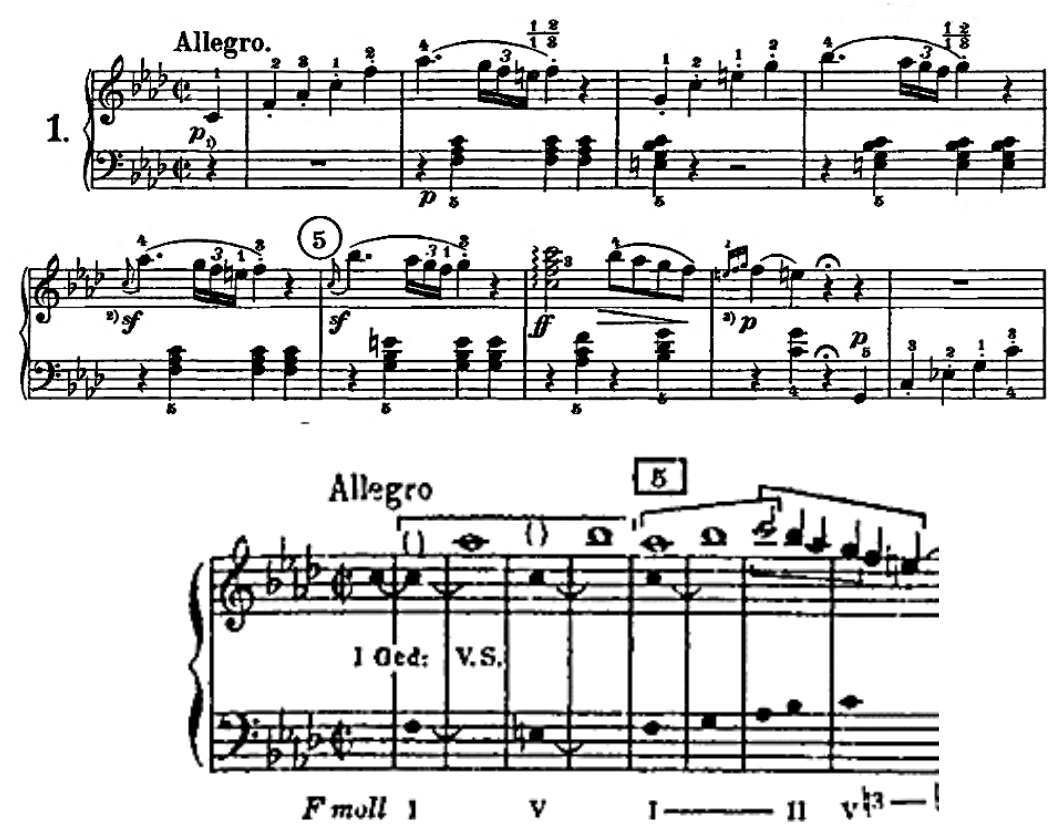

Fig. 4 - Beethoven, Sonata Op. 2 n. 1, para piano, I (compassos 1-8) - Fatores temporais e gráfico do plano intermediário. Fig. 4a: Excerto do Primeiro Movimento; Fig. 4b: Excerto de gráfico do plano intermediário.

Fonte: Schenker (2004 [1922], p.72).

O emprego da pedalização apresenta-se como outra questão pragmática em parte dos estudos prescritivos de Schenker. A possibilidade de emprego do conhecimento harmônico no tratamento de questões pragmáticas relacionadas à pedalização foi 
tratada em seu estudo sobre o primeiro movimento da Sonata para piano em Fá menor Op. 57 n. 1, de Beethoven. Nele, Schenker (2005 [1924], p.57) prescreveu pedalização a partir de seu conhecimento sobre o evento harmônico, especificamente o emprego de acordes de sétima diminuta entre os compassos 47 e 50 . Em vez de uma única pedalização no trecho mencionado, Schenker (2005 [1924], p.45) propôs uma troca de pedal a cada novo acorde de sétima diminuta: "O trecho rápido dos compassos 47-50, que projeta o submotivo Fab-Mib [...], uma série de cinco acordes de sétima diminuta Fab-Sol que são conectados pelo Solb a fim de evitar uma segunda aumentada (Sol-Fab)". ${ }^{23} \mathrm{Na}$ figura 5, reproduzimos um excerto da sonata mencionada.
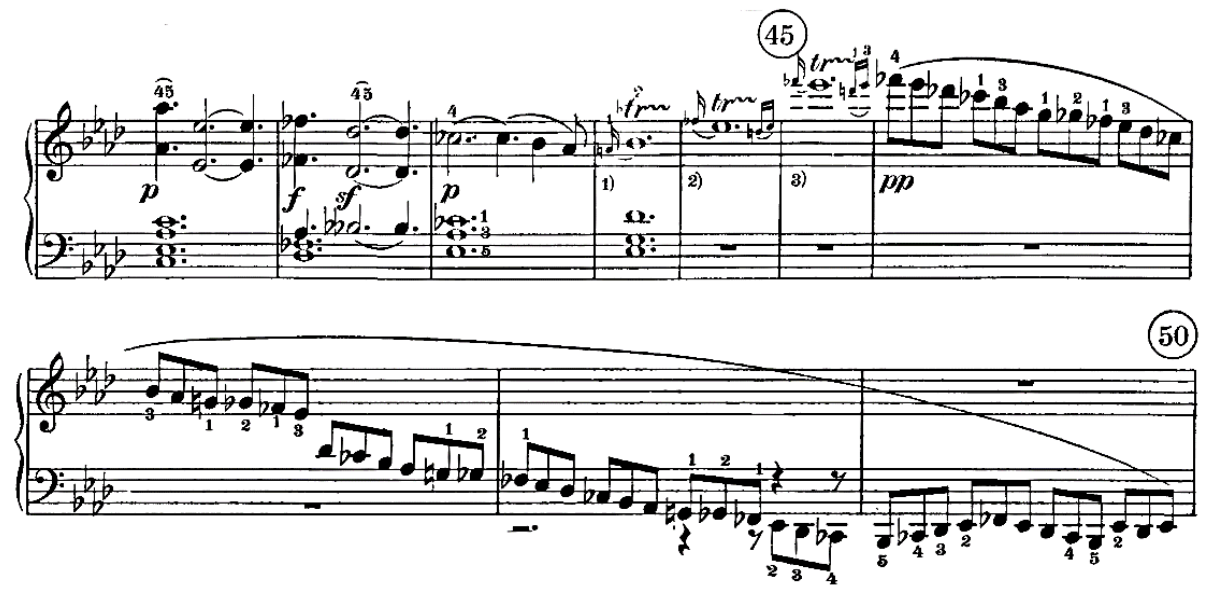

Fig. 5 - Beethoven, Sonata Op. 57 n. 23, para piano, I (compassos 47-50) - Pedalização dos acordes de sétima diminuta. Fonte: Beethoven (1975 [1804-1806]).

A mesma estratégia de pedalização é proposta aos compassos 186 a 189. Com base em sua interpretação harmônica, Schenker (2005 [1924], p.59) sugeriu: "A partir do compasso 186, o pedal deveria novamente ser dividido (no lugar de um único pedal) em conformidade com os acordes de sétima diminuta, como nos compassos 47-50"24. $\mathrm{Na}$ figura 6, reproduzimos excerto do trecho em questão.

23 Original: "The run in bars 47-50 projects the submotive fb-eb [...] it is a series of five diminished-seventh chords fb-g that are connected by gb for the sake of avoiding an augmented second (g-fb)" (SCHENKER, 2005 [1924], p.45).

24 Original: "In bars 186ff the pedal should again be divided (in place of a single pedal) in conformity with the diminished-seventh chords, as in bars 47-50" (SCHENKER, 2005 [1924], p.59). 

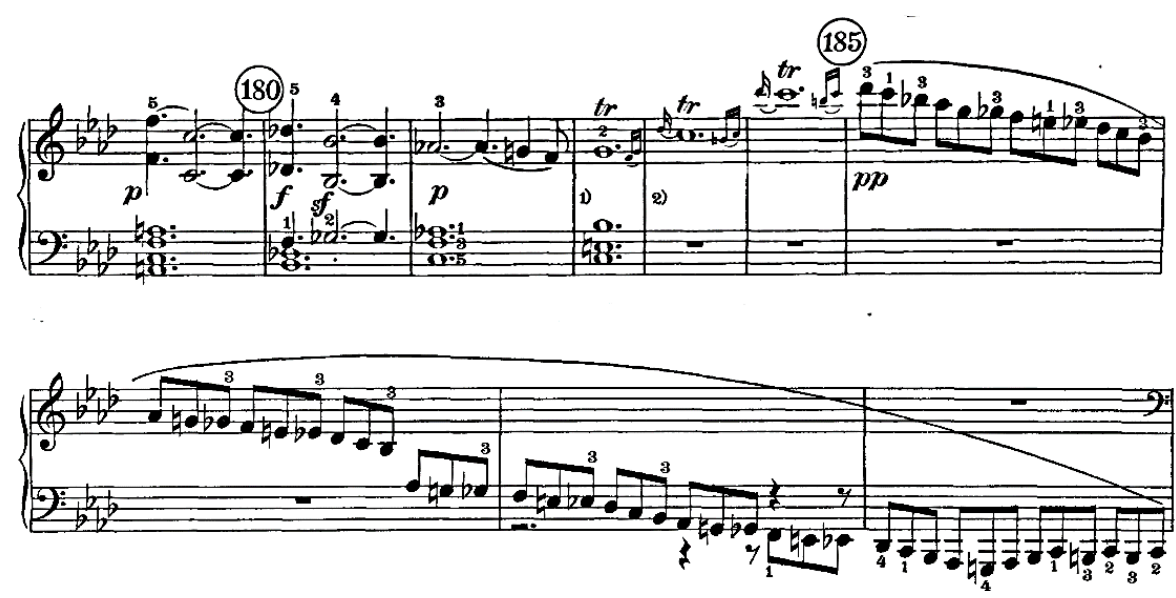

Fig. 6 - Beethoven, Sonata Op. 57 n. 23, para piano, I (compassos 185-189) - Pedalização dos acordes de sétima diminuta. Fonte: Beethoven (1975 [1804-1806]).

Além de extrair estratégia de pedalização com base no conhecimento de eventos harmônicos, Schenker apresenta sua proposta de projeção sonora para o trecho compreendido entre os compassos 46 e 50. Em seu gráfico do plano frontal (foreground), o teórico destacou a presença do submotivo Fab-Mib em diferentes trechos do primeiro movimento da Sonata em Fá Menor para piano Op. 57, de Beethoven. Em sua narrativa direcionada aos performers, o teórico prescreve o destaque sonoro destes motivos, reconhecidos em menor e em maior proporção: "As primeiras e últimas colcheias do trecho rápido entre os compassos 47-50 (Fab e Mib) devem ser conectadas por um >; a diminuição rítmica (Fab-Mib) no compasso 50 requer o mesmo tratamento"25(SCHENKER, 2005 [1924], p.57). Aqui, ele procura "justificar" sua proposta de projeção sonora em um achado analítico relacionado à projeção motívica.

Contudo, tal aspecto não foi apresentado como uma regra nas abordagens de Schenker. A ideia de que nem todo conteúdo revelado pela estrutura deveria implicar uma ênfase de determinado achado já transparece em algumas narrativas deste teórico. Como exemplo, podemos citar sua narrativa que trata da projeção sonora do compasso 21 do primeiro movimento da Sonata Op. 57 n. 23, de Beethoven. Schenker (2005 [1924], p.61) observou: "A nota da Urlinie, no tempo forte do compasso 21 [Dó], é entregue sem a intervenção do performer; a condução de vozes e a métrica a suportam para que o nosso ouvido tenha certeza de sua existência, mesmo que ela permaneça obscura". ${ }^{26}$ Em seu gráfico do plano frontal, Schenker (2005 [1924], p.43) destacou o motivo da Urlinie Do-Ré-Do (compassos 3-4), que também aparece no compasso 21. Na figura 7, reproduzimos excerto do trecho discutido por ele.

\footnotetext{
25 Original: "The first and last eighths of the run in bars 47-50 (fb and $\mathrm{Eb}$ ) must be tied together by >; the rhythmic diminution (Fb-Eb) in bar 50 requires the same treatment" (SCHENKER, 2005 [1924], p.57).

26 Original: "The Urlinie tone on the downbeat of bar 21 is delivered without the performer's doing: the voice-leading and meter support it, so that our ear can be sure of it even if it falls in the shadows" (SCHENKER, 2005 [1924], p.61).
} 


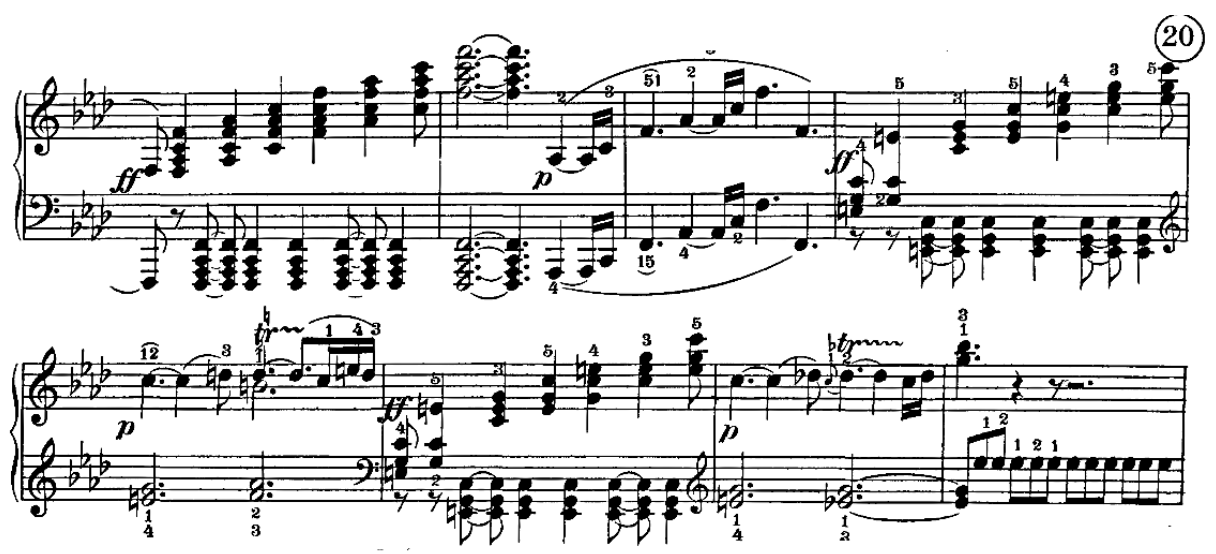

Fig. 7 - Beethoven, Sonata Op. 57 n. 23, para piano, I (comp. 17-24) - Projeção sonora. Fonte: Beethoven (1975 [1804-1806]).

A realização do estudo apresentado sobre Schenker não teve como propósito uma abordagem minuciosa acerca do tratamento conferido por ele às suas prescrições para a performance. Antes, nosso intuito foi verificar de maneira geral algumas das características e preocupações que acompanharam suas narrativas analíticas e prescritivas. De fato, sua narrativa revela o tom imperativo de suas prescrições. Por outro lado, pudemos notar possibilidades válidas ainda hoje de emprego do conhecimento da estrutura para a seleção de estratégias relacionadas à modelagem de diferentes aspectos, tais como a dinâmica, o tempo, o fraseado e a pedalização.

Neste sentido, constatamos a abrangência e a permeabilidade da "filosofia de performance" da primeira fase schenkeriana, não apenas junto à literatura analítica da segunda fase, como servido de base para boa parte dos trabalhos pedagógicos neoschenkerianos escritos por seus revisores, como veremos.

\section{A influência schenkeriana em abordagens da relação entre a aná- lise e a performance, nas propostas de Charles Burkhart, Steve Larson, Carl Schachter e David Beach}

Em seu livro Beyond the Score, Nicholas Cook (2013, p.34) discute o impacto da teoria schenkeriana nos estudos da subárea Análise e Performance Musical e trata também da disseminação das ideias de Schenker na literatura analítica americana. A origem dessa disseminação na década de 1950 pode ser relacionada a diferentes fatores, dentre os quais destacamos as anteriormente citadas vinculações do rigor do método de Schenker com configurações do método científico, assim respondendo a anseios de intelectuais da época, e com o contexto neopositivista do pós-guerra. Kerman (1987, p.108, tradução nossa) acrescenta: 
A análise schenkeriana não é fácil - requer muito trabalho e exercício constante de julgamento musical -, mas é eminentemente exequível. Mostra-nos como nos ajustarmos à tarefa e como localizar com precisão todas as notas numa composição sobre (ou em) os interstícios entre os gráficos desta ou daquela camada hierárquica. Os famosos gráficos de Schenker, usando principalmente a notação musical, evitam necessidade de muita prosa na análise [...]. O tematicismo e a análise schenkeriana, como eu disse, foram bem calculados para florescer na atmosfera positivista da década de $50 .{ }^{27}$

O teórico William Rothstein propôs uma interpretação dos possíveis fatores que favoreceram a divulgação das ideias de Schenker no contexto acadêmico estadunidense e o expressivo interesse das editoras americanas por publicações com conteúdo schenkeriano na década de 1980. Segundo Rothstein (1990, p.194), a publicação dos livros de harmonia de Aldwell e Schachter em 1978 impulsionou essa retomada. No decorrer dos próximos anos, o contexto vivenciado na cidade de Nova York foi um ambiente propício e receptivo às ideias de Schenker, em função da grande circulação de ideias derivadas de diferentes escolas de pensamento estrangeiras, como o trotskismo e o freudianismo. Neste sentido, Rothstein (1990, p.199) destaca dois centros acadêmicos dessa cidade como fortes propagadores dessas ideias, o Mannes College e o New York City University (CUNY). Contudo, conforme consta no relato de Rothstein (1990, p.194), suas ideias não ficaram limitadas a esses centros acadêmicos, tendo se propagado para centros localizados em outros estados americanos.

O autor menciona um terceiro aspecto favorável ao processo de "americanização de Heinrich Schenker". Voltando-se ao processo editorial de Free Composition (1935), Rothstein (1990, p.196) observou a omissão de um apêndice dessa publicação pelos editores a fim de preservar a imagem de Schenker em relação a algumas de suas posturas políticas, uma vez que o teórico vinha sendo bastante criticado por sua concepção musical absolutista e pelo nacionalismo exacerbado, quanto à linha de pensamento segundo a qual a verdade de uma obra musical só poderia ser revelada a partir das obras-primas de tradição predominantemente alemã.

A tentativa de suavizar os posicionamentos defendidos por Schenker também foi concretizada em publicações de teóricos influenciados por sua teoria. Como exemplo, Rothstein destaca a boa recepção do livro Structural Hearing, do teórico americano Felix Salzer, publicado em 1962. Esse livro faz uso de princípios da ferramenta schenkeriana no estudo de repertório não tonal, empregando-os de maneira não ortodoxa. Na opinião de Rothstein (1990, p.198-200), a organização, a compreensibilidade e a flexibilidade de pensamento foram fatores que favoreceram a recepção da teoria de Schenker através da publicação de Salzer. O aproveitamento da teoria schenkeriana a partir de um discurso mais flexível foi também uma tendência no trabalho de Carl Schachter e Charles Burkhart.

27 Original: "Schenkerian analysis is not easy - it requires a lot of work and the constant exercise of musical judgment-but it is eminently doable. It shows you how to get on with the job and how to pinpoint every note in a composition either on or in the interstices between the graphs of this or that hierarchical layer. Schenker's famous graphs, using mainly musical notation, preclude the necessity for much prose in the analysis [...]. Both, thematicism and Schenkerian analysis, as I have said, were well calculated to flourish in the positivistic atmosphere of the 1950 s" $^{\prime}$ (KERMAN, 1987, p.108). 
A partir desse breve contexto, que permite compreender parcialmente aspectos que podem ter favorecido a propagação das ideias de Schenker, daremos continuidade à nossa abordagem focando a performance, uma vez que a influência de Schenker não ocorreu somente em relação ao aproveitamento de sua teoria analítica, mas foi concretizada a partir de sua concepção de performance musical.

Dentre os estudos que nos serviram de base, temos alguns dos desenvolvidos por Charles Burkhart (1983, 1994), Steve Larson (1983), Carl Schachter (1991, 1994, 2000) e David Beach $(1987,1998)$. Todos são teóricos americanos com experiência em performance. Sobre tais autores, Cook (2013, p.35) observou: "Hoje, a pedagogia schenkeriana da performance é em essência a obra dos schenkerianos do pós-guerra, desde Charles Burkhart e Edward Laufer até Carl Schachter e William Rothstein". ${ }^{28}$ Embora Cook não mencione os nomes de Steve Larson e David Beach, ${ }^{29}$ o compromisso destes autores com a pedagogia schenkeriana poderá ser notado a seguir.

Um primeiro aspecto reconhecido nos estudos trata da similaridade organizacional. Semelhantemente a Schenker, Larson (1983), Schachter (1991) e Burkhart (1994) propuseram estudos caracterizados pela separação entre as considerações analíticas da estrutura e aquelas sobre performance musical. Assim, reconhecemos a adesão desses autores a um estilo de organização marcado pela apresentação de longas considerações estruturais, seguidas de prescrições aos performers, apresentadas em fins dos estudos.

Podemos afirmar que o aproveitamento da teoria schenkeriana ocorreu de maneira não ortodoxa. É o caso de algumas das abordagens de Burkhart (1994), Beach (1987) e Schachter (2000), que se caracterizaram pelo emprego de pressupostos defendidos por Schenker, desvinculados da apresentação de gráficos em multiníveis aplicados à totalidade de uma obra musical. Entretanto, a influência da ideologia organicista permanece mediante o interesse pela compreensão da inter-relação entre as diferentes partes no todo, ainda que este todo tenha se limitado a menores dimensões da totalidade de uma obra musical. A busca pela compreensão orgânica de uma obra musical por meio da percepção do funcionamento das partes foi considerada característica da ideologia organicista presente nas abordagens de Schenker (BEARD; GLOAG, 2005, p.124).

Paralelamente ao emprego não ortodoxo, há na nossa amostragem um aspecto relacionado ao interesse pela extensão de pressupostos defendidos por Schenker no estudo de parâmetros, como ritmo, flexibilizações do tempo métrico, dinâmica e articulação.

\footnotetext{
28 Original: "[...] today's Schenkerian performance pedagogy is in essence the work of post-war Schenkerians from Charles Burkhart and Edward Laufer to Carl Schachter and William Rothstein" (COOK, 2013, p.35).

29 No caso de Beach, seu interesse pela divulgação da teoria schenkeriana é evidenciada no livro que organizou em 1983, Aspects of Schenkerian Theory, assim como pelo seu estudo Schenker's Theories: A Pedagogical View (BEACH, 1983, p.16).
} 


\subsection{A proposta neoschenkeriana de Steve Larson: vinculação entre a identifica- ção de hipercompassos e o estabelecimento de agrupamentos}

Como primeiro exemplo, podemos mencionar o estudo de Larson (1983), que procurou estender a ideia de multiníveis estruturais ao estudo do ritmo. Larson buscou demonstrar uma compreensão mais profunda dos aspectos rítmicos e métricos a partir de sua proposta gráfica de redução duracional, baseada na Invenção a duas vozes n. 1 em Dó maior, de J. S. Bach (Fig. 8).
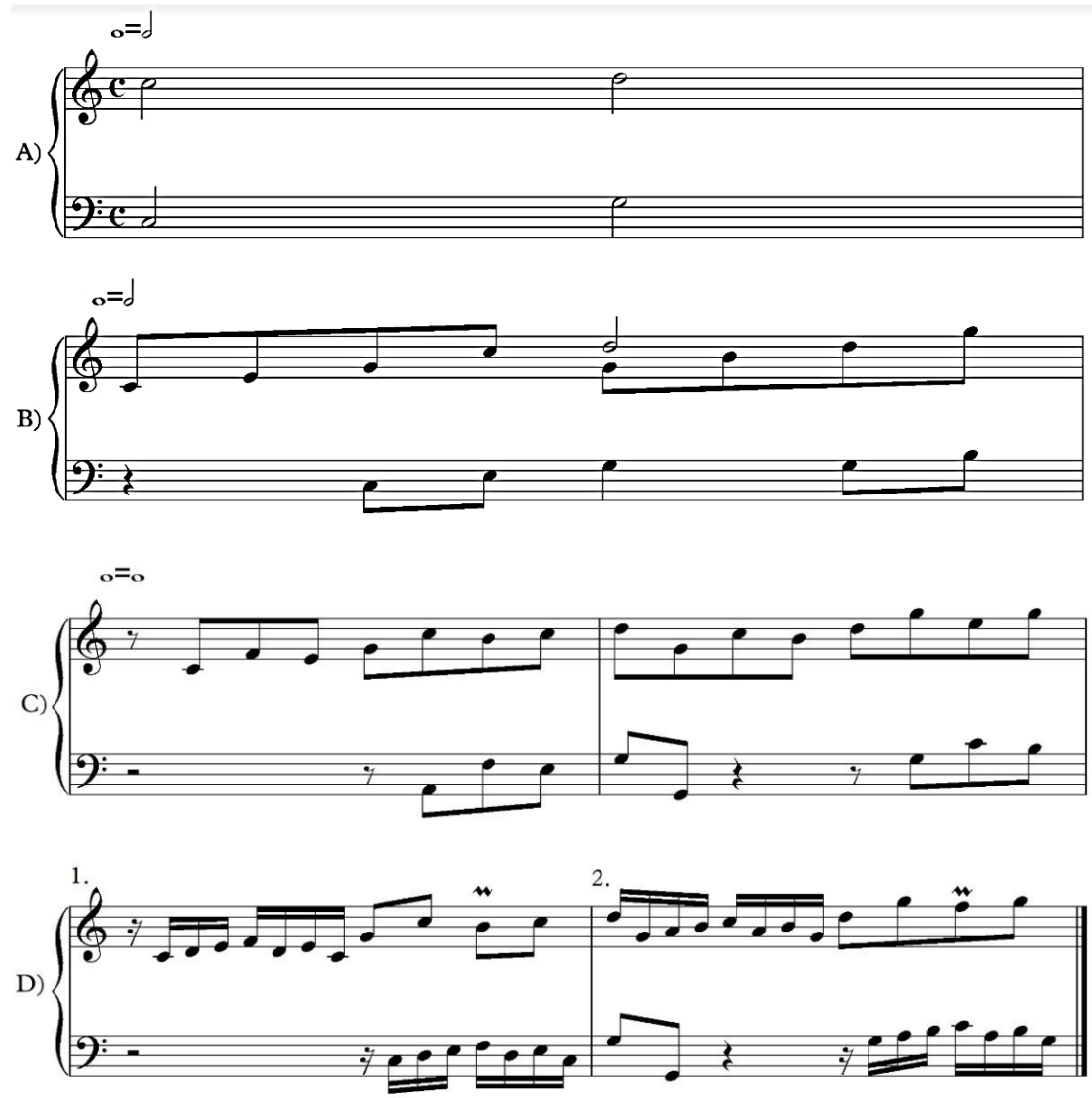

Fig. 8 - J. S. Bach, Invenção a duas vozes, n. 1, em Dó maior (compassos 1 e 2) - Gráfico de redução duracional, distribuído entre as diferentes camadas estruturais.

Fonte: Larson (1983, p.32).

Apesar do alto teor prescritivo deste estudo, encontramos em seu discurso a ideia em favor do potencial do conhecimento estrutural para a tomada de decisões pelo performer, como as questões atreladas ao estabelecimento de agrupamentos e fraseado (LARSON, 1983, p.44), sendo estabelecida uma complementaridade metodológica entre as análises da métrica e de vozes condutoras. Em relação o exemplo sobre essa Invenção de Bach (Fig. 9), o teórico menciona o "caráter anacrústico" (LARSON, 1983, p.40) dos 
compassos 1 a 2, tratado a partir do reconhecimento de uma ascensão inicial ${ }^{30}$ e de um hipercompasso ${ }^{31}$ (compassos 3 a 6):
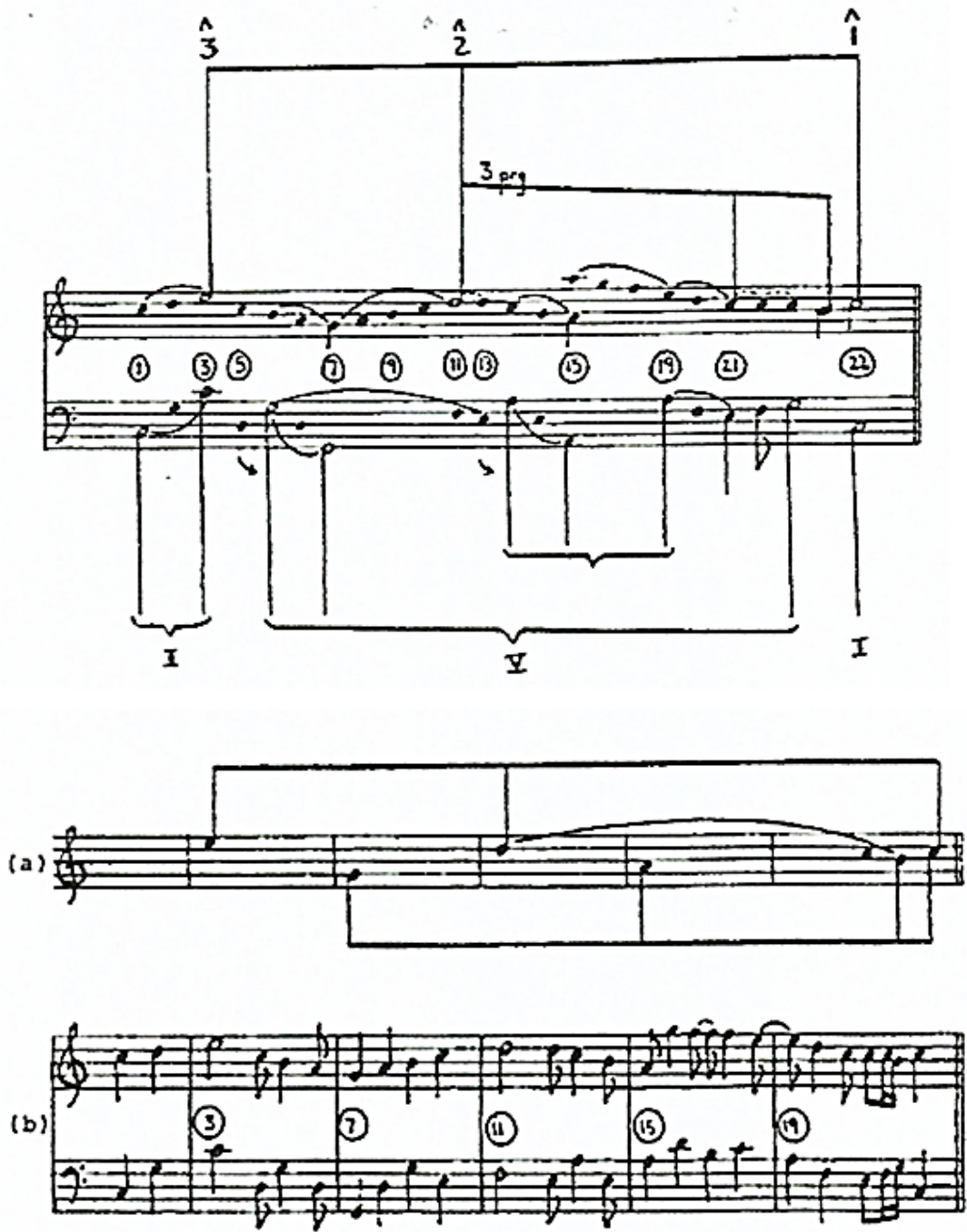

Fig. 9 - J. S. Bach, Invenção a duas vozes, n. 1, em Dó maior - Esquemas representativos da Urlinie e hipercompassos. Fig. 9a: Representação da Urlinie; Fig. 9b: Representação gráfica em favor da ideia de hipercompassos.

Fonte: Larson (1983, p.19).

30 Em seu livro, Fraga (2009, p.34) define a ascensão inicial como um "movimento ascendente por grau conjunto ou arpejo de tríade (ou ainda uma combinação de ambos) que parte de uma nota da tríade de tônica em direção à primeira nota" da linha fundamental.

31 O conceito de hipercompasso foi tratado por Edward Cone no livro Musical Form and Musical Performance (1968). É compreendido como o agrupamento de vários compassos, contados como se fossem uma unidade métrica (CONE, 1968, p.80-82). 


\subsection{A proposta neoschenkeriana de Charles Burkhart: vinculação en- tre métrica e os desafios de articulação e dinâmica}

Em Burkhart (1994), verificamos os esforços não apenas para demonstrar a interlocução entre as vozes condutoras e o mid-bar downbeat, ${ }^{32}$ mas o potencial deste conhecimento para as questões de modelagem sonora (dinâmica, tempo e articulação). Como Larson (1983), Burkhart também considerou a insuficiência de uma abordagem focada num único parâmetro quando o propósito é proporcionar contribuições ao performer. $\mathrm{Na}$ figura a seguir, apresentamos um esquema representativo de ambos os aspectos com base na Invenção a duas vozes em Lá menor, n. 13, de J. S. Bach. Na Fig. 10a, é ilustrada a relação entre o mid-bar donwbeat e o aparecimento de suspensões. A Fig. 10b mostra a relação entre o tempo métrico forte e o ponto de chegada da Urlinie, bem como a presença de um hipercompasso.

a) mm. 8b-15. See successive downbeats at N.B.
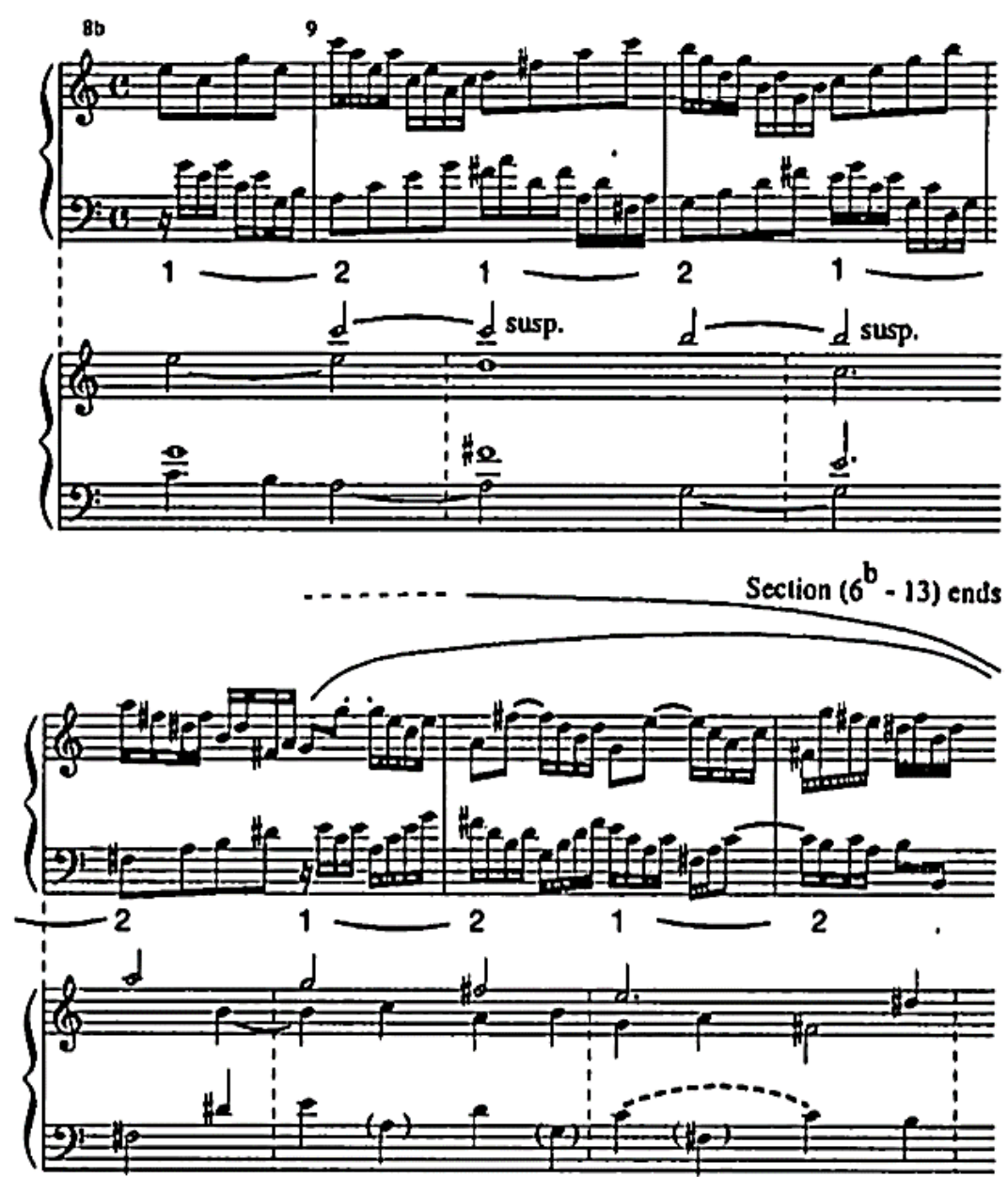

32 O artigo de Burkhart (1994) inicia com uma breve explanação acerca do mid-bar downbeat, que nada mais é do que o deslocamento do tempo forte de sua posição métrica normal. Sobre esse fenômeno, observou: "All musicians will recall confronting passages in which the downbeat seems to fall in the middle of the bar - passages in which the player (or listener) feels '1 234 ' when the score is actually saying $34 \mid 12$. I will call this phenomenon mid-bar downbeat. It can occur only in duple meters, of course - most readily in those with four pulses to the bar" (BURKHART, 1994, p.3). "Todos os músicos se lembrarão de passagens em que o tempo forte parece cair no meio do compasso - passagens em que o músico (ou ouvinte) sente ' 1234 ' quando a partitura está realmente dizendo 34 | 12 . Eu chamarei este fenômeno de tempo forte no meio do compasso. Pode ocorrer apenas em métricas duplas, é claro - mais especificamente naquelas com quatro pulsos no compasso" (BURKHART, 1994, p.3). 


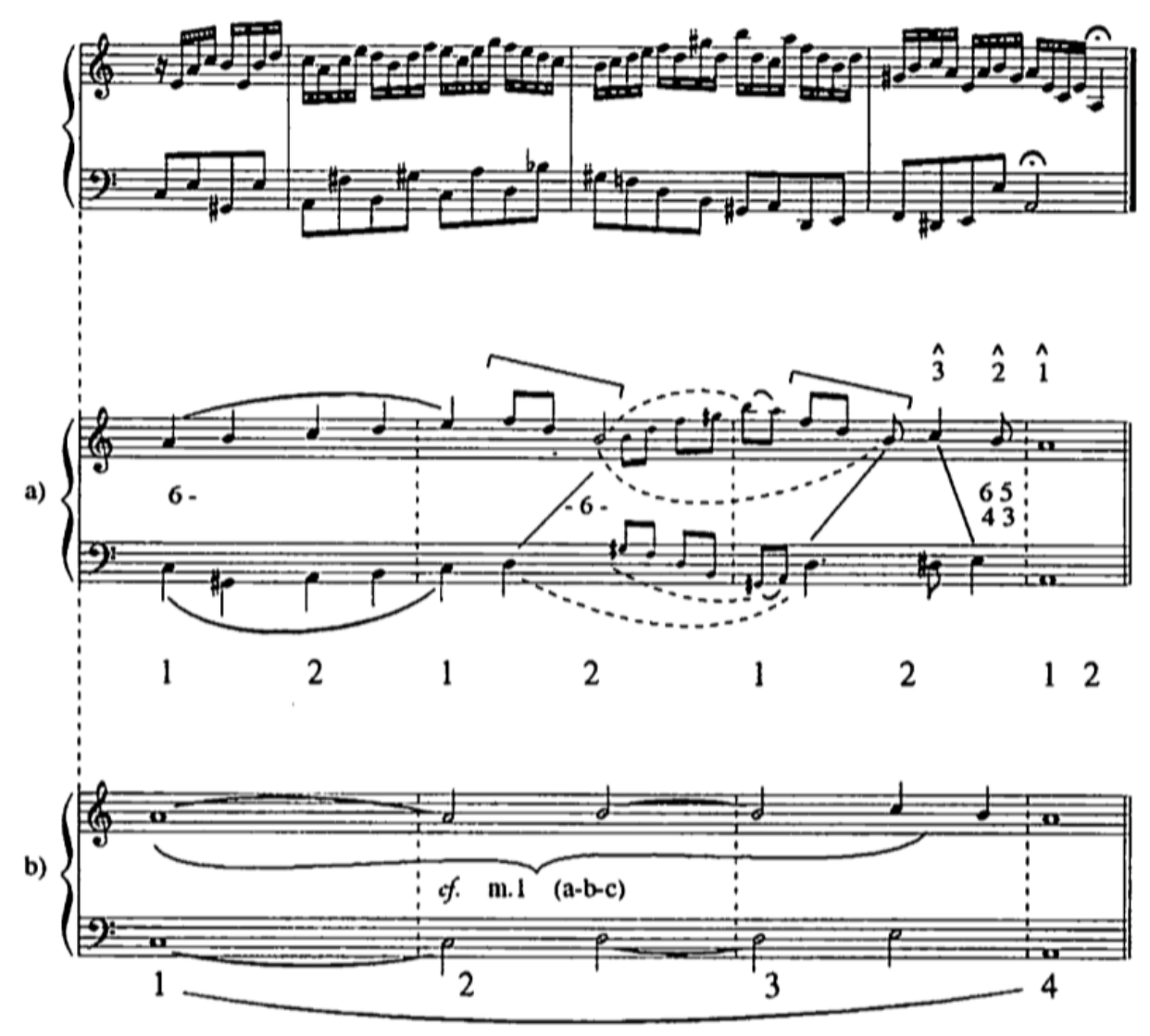

Fig. 10 - J. S. Bach, Invenção a duas vozes, n. 13, em Lá menor - Esquemas representativos do mid-bar downbeat e sua relação com as vozes condutoras. Fig. 10a (com 2 sistemas): Relação entre suspensões e tempo métrico forte; Fig. 10b: Relação entre ponto de chegada da Urlinie e tempo métrico forte.

Fonte: Burkhart (1994, p.17).

A modelagem da dinâmica com base no conhecimento de eventos estruturais harmônicos e da síntese estrutural é outra preocupação de Burkhart, assim como consta em muitos estudos analíticos de Schenker. Um exemplo conhecido dessa relação é que trechos caracterizados pela resolução de dissonâncias sugerem a ênfase em notas e acordes dissonantes em relação às suas resoluções. Tal procedimento é nítido em Burkhart (1983, p.103), em sua abordagem do Improviso em Fá\# Maior Op. 36, de Chopin. Nela, o teórico extrai recursos para a modelagem da dinâmica a partir do reconhecimento de notas dissonantes que integram o motivo formado sobre o intervalo de $2^{\underline{a}}$ menor. Em outras palavras, o teórico demonstra como o senso de hierarquia entre notas ornamentais e estruturais pode colaborar para a modelagem de dinâmica. Sua sugestão interpretativa é clara: "[...] os motivos de duas notas podem ser realizados por meio de uma suave ênfase [...] à primeira nota de cada um deles [...]. Cada primeira nota é uma apojatura em tempo fraco, e sua dissonância seguida pela resolução deve ser o mais clara possível"33 (BURKHART, 1983, p.104). No esquema a seguir (Fig. 11), o autor procura ilustrar o emprego motívico em diferentes trechos da obra em estudo.

33 Original: "[...] the two notes' motives can be achieved by giving a very slight emphasis [...] to the first note of each one [...]. Each first note is a weak-beat appogiatura and its dissonance followed by resolution should be as clear as possible" (BURKHART, 1983, p.104). 

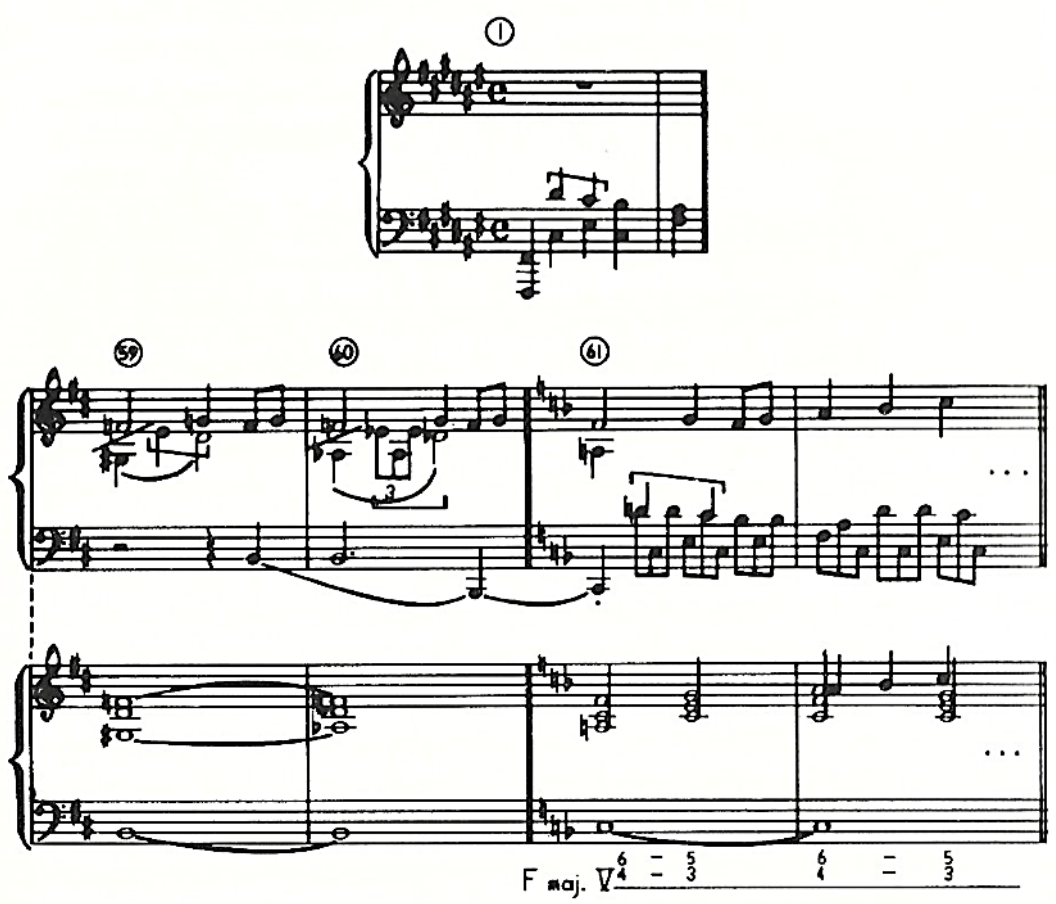

Fig. 11 - Chopin, Improviso Op. 36 (comp. 1-2, 59-62) - Emprego motívico.

Fonte: Burkhart (1983, p.103).

Em relação a articulação e fraseado, ${ }^{34}$ autores como Burkhart (1994), Schachter (1994), Beach (1987) e Larson (1983) apresentam os agrupamentos de eventos e fraseados formados a partir do exame da métrica e de sua interlocução com as vozes condutoras (LARSON, 1983, p.39; BURKHART, 1994, p.11; SCHACHTER, 1994, p.39). Neles, a análise rigorosa é empregada com o propósito de revelar a presença de uma métrica obscurecida ou latente. Em Burkhart (1994), a identificação do mid-bar downbeat foi apresentada como uma possibilidade de colaborar com a fluidez de um fraseado pelo performer. Segundo o teórico, o reconhecimento deste procedimento, bastante presente na música de J. S. Bach, poderia conscientizar o performer acerca dos deslocamentos métricos em meios do compasso, favorecendo a identificação de inícios e finais de frases musicais. A figura 12 é um excerto da Allemande da Suíte francesa n. 6, de J. S. Bach. A partir dela, o teórico ilustrou o emprego da elisão, ${ }^{35}$ cujo conhecimento serviu-lhe de recurso para fazer prescrições à dinâmica, ao tempo e à articulação.

34 Com base em estudos de Berry (1989, p.3) e Chew (2001), podemos definir a articulação como um aspecto implícito no fraseado, que por sua vez se refere ao agrupamento de eventos. Segundo Chew (2001), ambos são elementos que contribuem para a diversidade orgânica, considerados aspectos de responsabilidade do intérprete. $O$ autor menciona diferentes tipos de articulação, por exemplo, o pizzicato e o legato.

35 Refere-se ao tipo de deslocamento da métrica ou mid-bar donwbeat caracterizado pela sobreposição de frases musicais (BURKHART, 1994, p.5). 


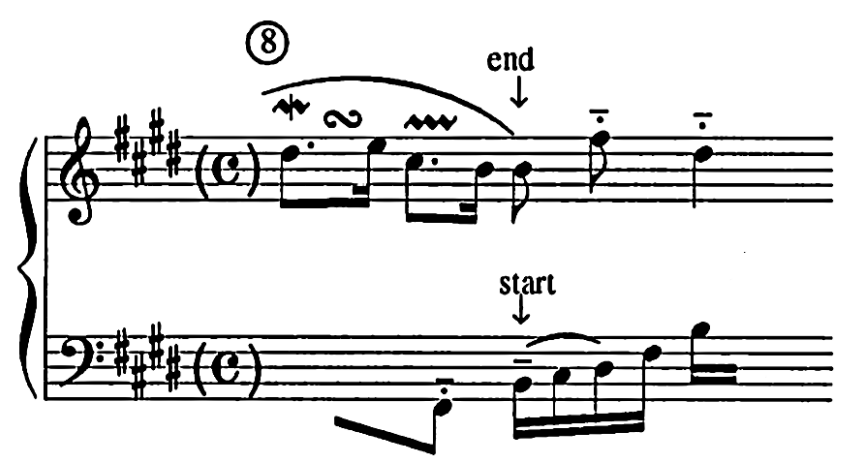

Fig. 12 - J. S. Bach, Suíte francesa, n. 6 - Elisão em trecho da Allemande. Fonte: Burkhart (1994, p.24).

Neste mesmo estudo, Burkhart interpretou a métrica em relação ao processo de condução de vozes a partir do Pequeno prelúdio n. 8, de J. S. Bach. Na Fig. 13b, o teórico faz prescrições (dinâmica e articulação) com base na inter-relação entre diferentes aspectos da estruturação musical: acordes estruturais, vozes condutoras e métrica implícita. No exemplo a seguir, o teórico prescreve ênfase dinâmica e toque mais robusto ao acorde estrutural (Fá maior), coincidente com um tempo métrico forte ou com o mid-bar downbeat (3ำ tempo do compasso 8 ):
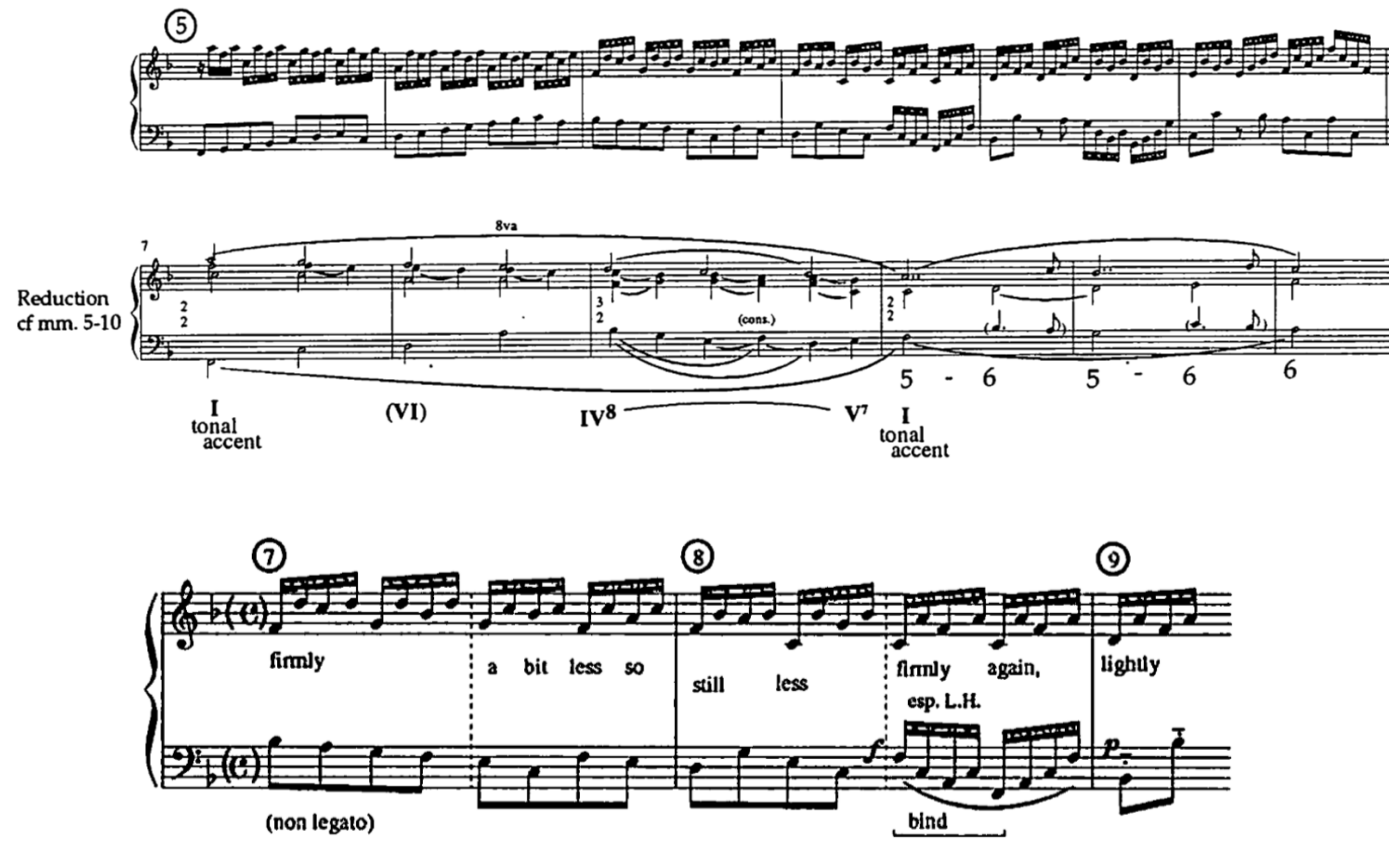

Fig. 13 - J. S. Bach, Pequeno prelúdio, n. 8 - Fig. 13a (2 sistemas): Interpretação métrica;

Fig. 13b: Esquema representativo de prescrição à performance.

Fonte: Burkhart (1994, p.11, 26). 


\subsection{A proposta neoschenkeriana de Carl Schachter: vinculações entre métrica e o estabelecimento da articulação, e entre vozes condutoras, métrica e agógica}

O interesse por uma abordagem mais abrangente sob o ponto de vista estrutural pode ser notado em algumas das propostas de Carl Schachter (1991, 1994, 2000), teórico que também buscou estender princípios da teoria schenkeriana à investigação do ritmo (MORGAN, 2014; COOK, 2013). Seu estudo sobre o Prelúdio n. 5 Op. 28, de Chopin, traz gráficos representativos da interlocução entre vozes condutoras e métrica. No caso de sua interpretação da métrica e do ritmo, vale observar aqui a influência da proposta de Cone (1968), uma vez que Schachter interpretou os compassos 1 a 4 (Fig. 14b) como um upbeat estendido, ${ }^{36}$ que assume a função de preparar a chegada de um downbeat estrutural (compasso 5, 1ำ tempo) ou ponto de chegada na tônica (SCHACHTER, 1994, p.32). Esta reinterpretação da métrica, que procura fornecer subsídios para a articulação de eventos estruturais da performance, é apresentada no exemplo a seguir.
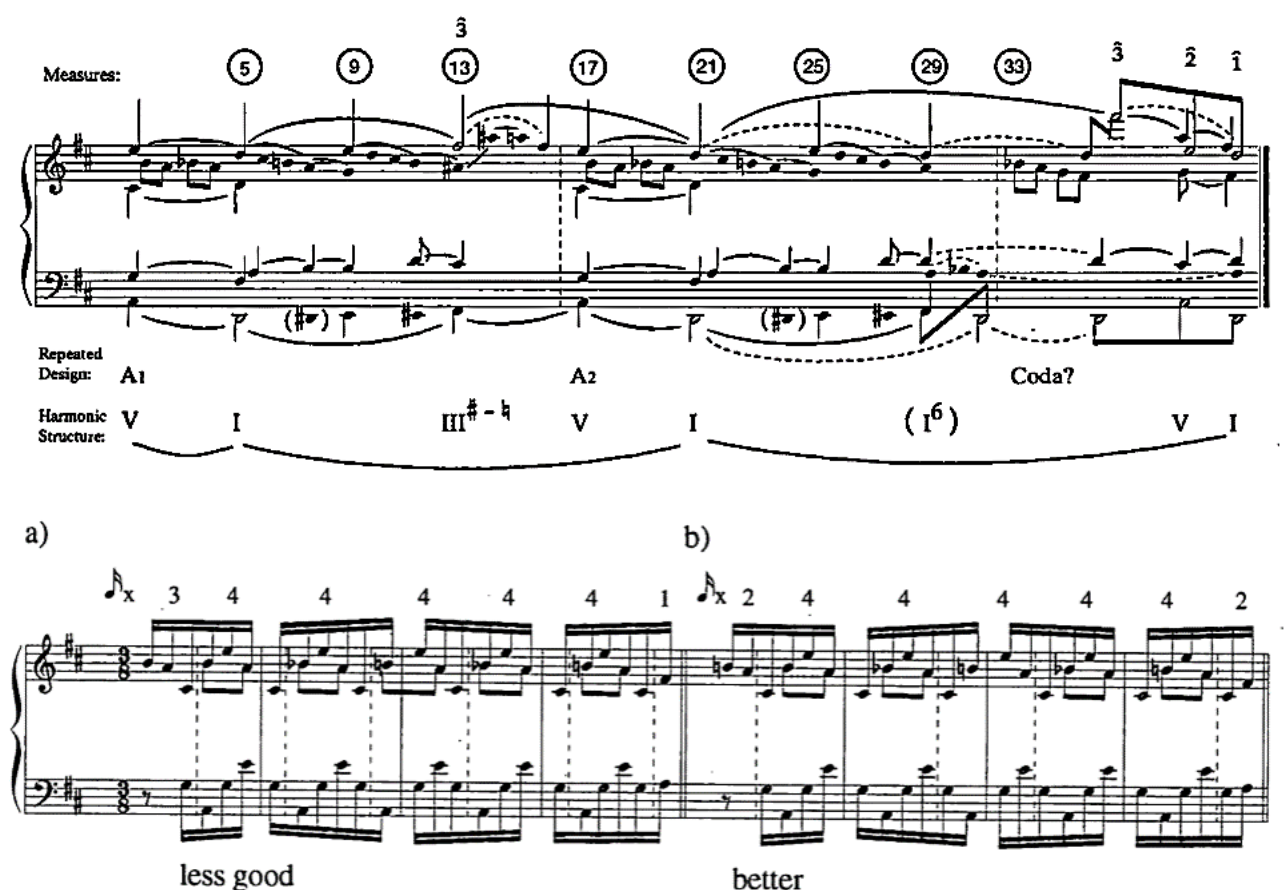

Fig. 14 - Chopin, Prelúdion. 5, Op. 28 - Esquemas de vozes condutoras e proposta de subdivisão rítmica.

Fig. 14a: Gráfico de vozes condutoras; Fig. 14b: Alternativas interpretativas à subdivisão rítmica.

Fonte: Schachter (1994, p.34).

36 Em seu estudo sobre a Sonata Op. 31 n. 3, de Beethoven, Cone (1968, p.24) define o "upbeat estendido" como uma espécie de preparação para uma progressão básica de uma peça. Ele se encontra presente em certas composições iniciadas em tonalidades diferentes ou distanciadas da tônica. 
O conhecimento harmônico e de vozes condutoras também tem sido empregado como estratégia às flexibilizações do tempo métrico da performance. Um exemplo conhecido é a introdução de um allargando em trechos cadenciais em fins de uma seção ou na transição entre diferentes seções. Schachter (2000) ilustrou este aspecto em seu estudo da Canção sem palavras n. 1 Op. 19, de Mendelssohn. Com base na percepção da relação entre prolongamento de acorde (Si maior, compassos 11 a 15) e uma cadência frustrada (compassos 12 e 13), o teórico/performer sugere um breve allargando do acorde de sétima diminuta (compasso 13, 1 tempo), por considerar que este acorde tem o papel de prolongar a harmonia de Si Maior, iniciada no compasso 11. Na visão do autor, um breve alargamento deste acorde poderia intensificar o efeito surpresa da cadência frustrada do compasso 13. O autor ainda sugere um breve allargando no compasso 10 , em virtude de este compasso estar no final de um espaço prolongacional, coincidente com a harmonia de Mi maior (compassos 1 a 10). Nos exemplos a seguir (Fig. 15), incluímos o excerto do trecho em questão e o gráfico de Schachter, baseado na notação schenkeriana.

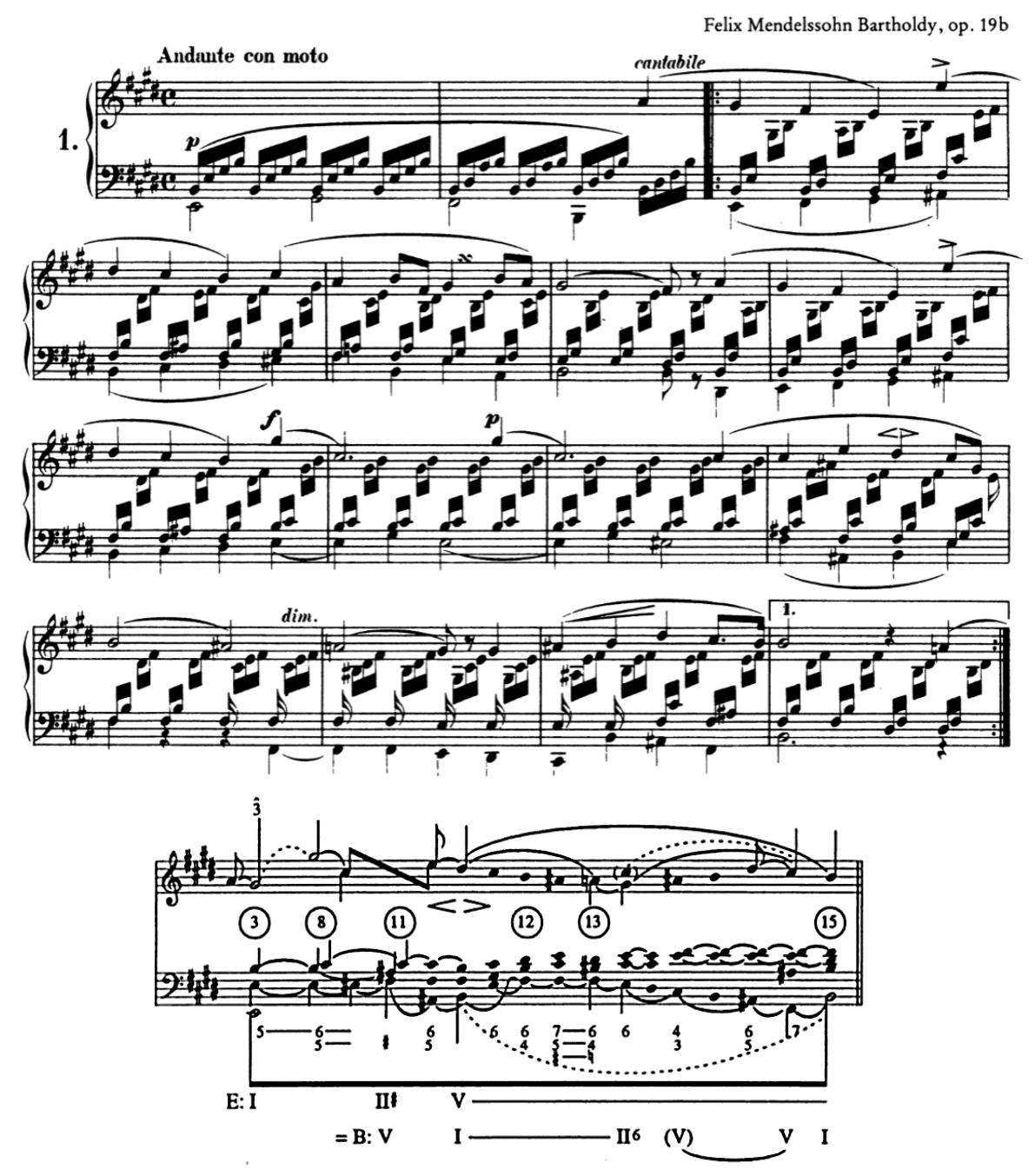

Fig. 15 - Mendelssohn, Canção sem palavras n. 1, Op. 19 - Excerto e plano subjacente.

Fig. 15a: Partitura (compassos 1-15). Fig. 15b: Gráfico de vozes condutoras.

Fontes: Fig. 15a - Mendelssohn (1877 [1829-1845]); Fig. 15b - Schachter (2000, p.95). 
Em relação à modelagem do fraseado, o estudo de Schachter (1994) também enfatiza a importância do conhecimento acerca da inter-relação entre vozes condutoras e o processo de agrupamento de eventos. Sua proposta prescritiva para os performers é apresentada na forma de um esquema representativo da agógica ou de flutuações temporais, o que ocorre ao final de seu estudo. No exemplo da Fig. 16, também baseado no Prelúdio n. 5 Op. 28, de Chopin, as setas que apontam para a direita são indicativas de acelerações no tempo métrico, e as setas apontadas para a esquerda sugerem o allargando temporal. Uma comparação deste esquema com o anterior permitirá ao leitor notar a sugestão de um allargando pouco antes da entrada do acorde estrutural (Ré maior, compasso 5), ou seja, trecho cadencial que antecipa a entrada de uma métrica forte no compasso 5.

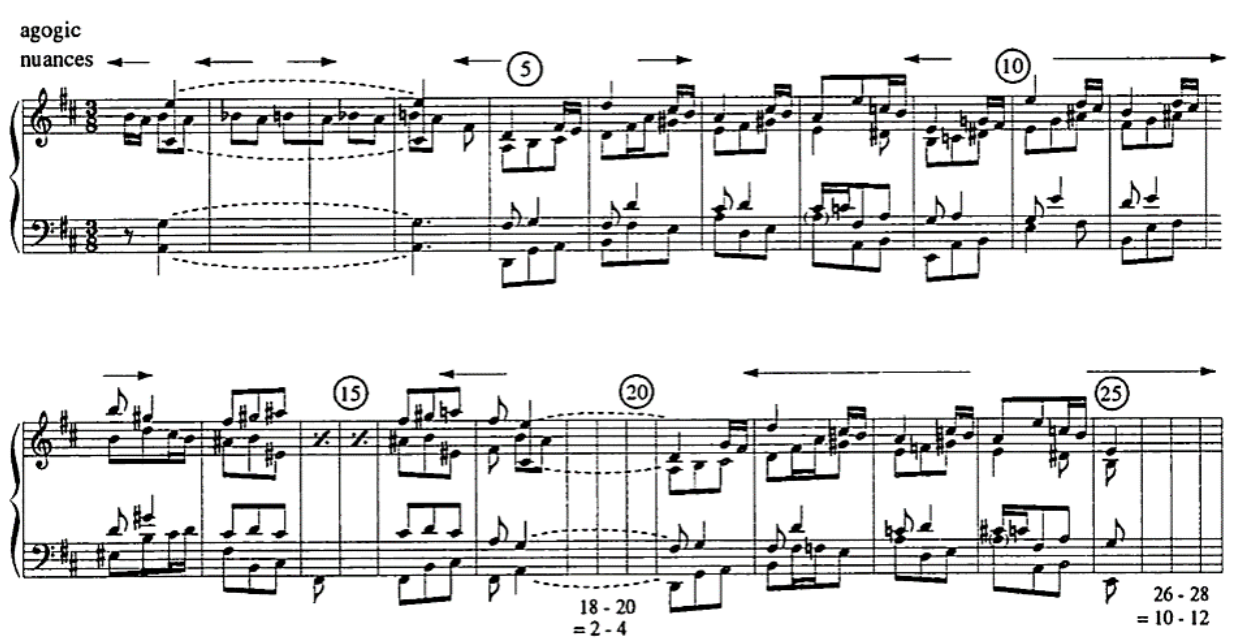

Fig. 16 - Chopin, Prelúdio n. 5, Op. 28. Esquema representativo das nuances de agógicas.

Fonte: Schachter (1994, p.43)

\subsection{A proposta neoschenkeriana de David Beach (1964): vinculação entre a identificação de hipermétrica e o estabelecimento de agrupa- mentos}

Um último exemplo de elaboração analítica focada na percepção da inter-relação entre vozes condutoras e métrica aparece no estudo de David Beach (1987) sobre o primeiro movimento da Sonata para piano em Lá menor (K. 310), de Mozart. Beach (1987, p.6) reafirma a importância de o performer desenvolver uma visão abrangente da estrutura. Neste sentido, defende tanto a visão em favor da observação da inter-relação entre diferentes elementos da estruturação quanto uma visão em larga escala de eventos harmônicos, melódicos e métricos (BEACH, 1987, p.178). Em seu estudo, ele argumenta a favor de uma hipermétrica, presente entre os compassos 23 a 49 da Sonata em questão. 
No esquema a seguir (Fig. 17), o autor apresenta uma abordagem interpretativa do plano médio e ilustrativa da ideia de quatro hipermétricas coincidentes com acordes estruturais. Diferentes visões hierárquicas estão presentes em um único esquema.
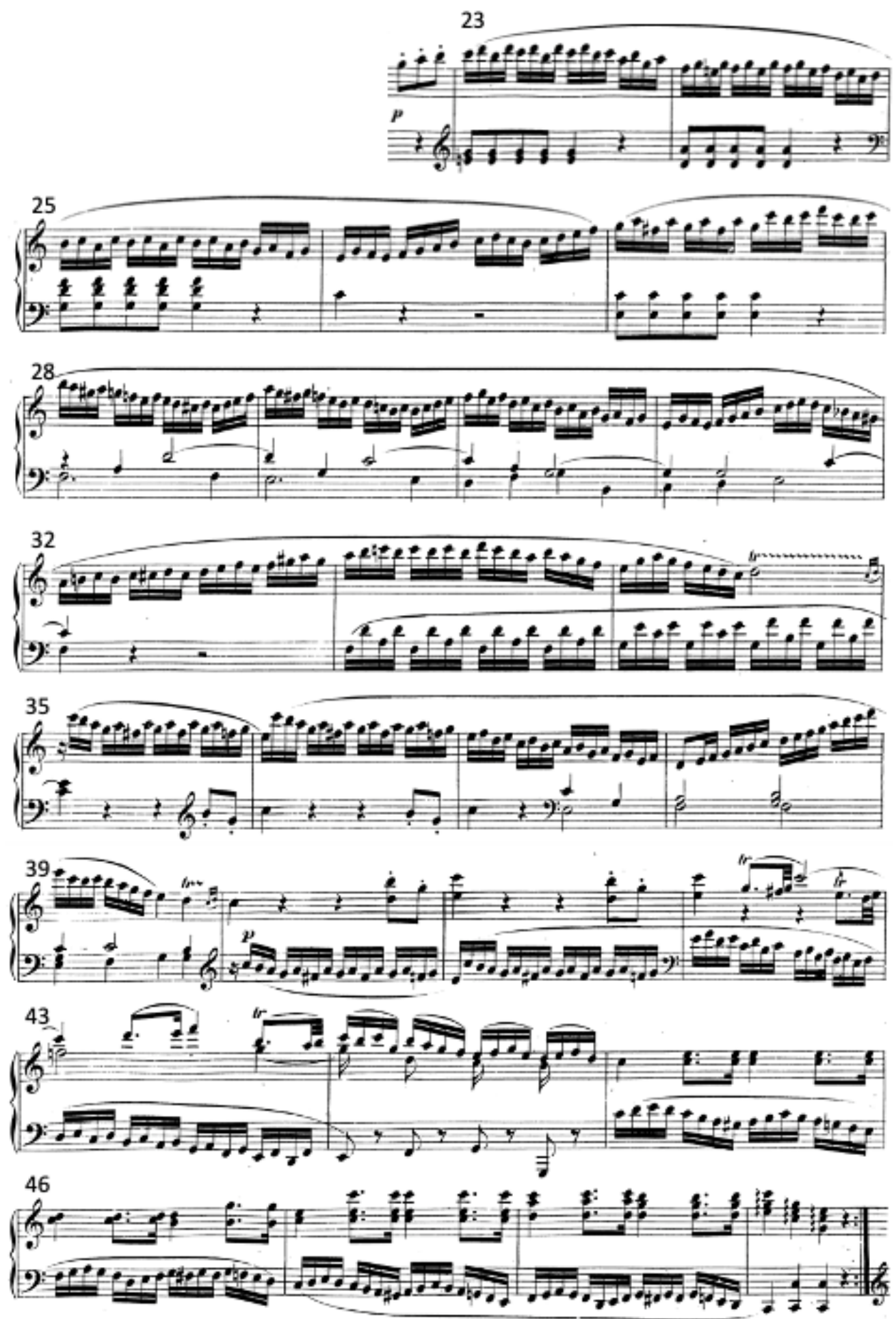


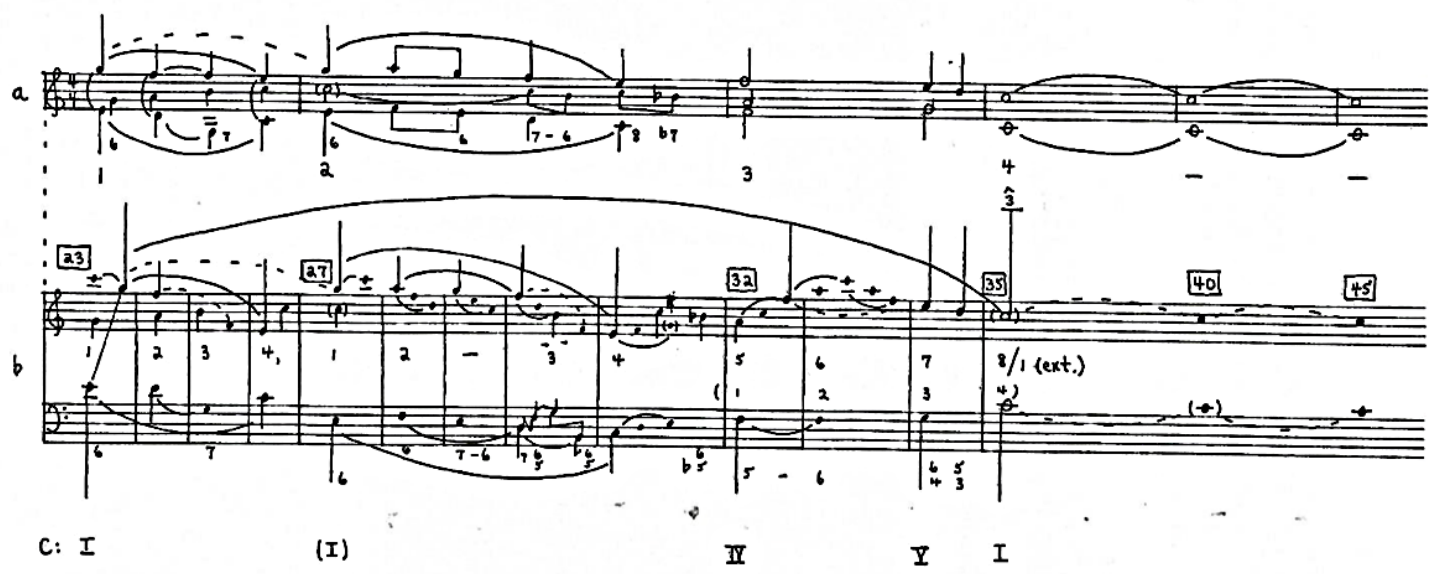

Fig. 17 - Mozart, Sonata para piano em Lá menor, K310, I - Gráfico do plano médio e hipermétricas.

Fig. 17a: Partitura (compassos 23-49); Fig. 17b: Gráfico de vozes condutoras.

Fonte: Fig. 17a - Mozart (1878 [1778]); Fig. 17b - Beach (1987, p.165).

\section{Considerações finais}

A partir dos estudos supracitados, acreditamos que certas considerações sobre as preocupações analíticas dos autores merecem atenção.

A primeira diz respeito ao interesse de teóricos neoschenkerianos pelo estudo de parâmetros que vão além da altura. Isso não deve denotar uma falta de interesse de Schenker por outros parâmetros musicais, mas, como bem observa Morgan (2014, p.204), "a capacidade de Schenker de explicar as características da superfície como derivações de uma fonte mais fundamental depende de seu foco na altura". ${ }^{37}$ Frente a esse contexto, teóricos neoschenkerianos (LARSON, 1983, p.31; SCHACHTER, 1991, p.620; BEACH, 1987, p.178; BURKHART, 1994) voltaram-se a questões pragmáticas sobre performance musical, ou seja, aquelas relacionadas à modelagem de parâmetros como dinâmica, tempo e articulação a partir de uma análise estrutural. Assim, os autores mencionados estenderam a "análise rigorosa" para que atingissem as questões mencionadas, tendo se provado capazes de propiciar insights interpretativos.

Tais estudos também reforçam a ideia da limitação da notação musical no que tange às indicações voltadas à execução. Cabe ao performer a tarefa de decidir a respeito das sutilezas de realização relacionadas a diversos parâmetros (dinâmica, tempo, articulação e fraseado). A noção em favor da incompletude da notação musical fica explícita no título de um dos estudos de Schachter: Playing What the Composer Didn't Write: Analysis and Rhythmic Aspects of Performance ("Executando o que o compositor não escreveu: análise e aspectos rítmicos da performance"). Nele, Schachter (2000, p.53) procurou mostrar a relevância da noção de prolongamento (melódico) para a modelagem temporal - especificamente, a consciência sobre os pontos de partida e chegada de certos tipos de movimentos lineares.

37 Original: "Schenker's ability to explain surface features as derivations from a more fundamental source depends upon his focus upon pitch [...]" (MORGAN, 2014, p.204). 
Quanto à forma de apresentação, Beach $(1987,1998)$ e Burkhart (1994) se caracterizaram por trazer longas considerações sobre a estruturação, seguidas de prescrições aos performers, ou seja, pela nítida separação entre o discurso analítico e aquele sobre performance musical. Tanto em Burkhart (1994) como em Beach (1987, p.157) e em Larson (1983, p.31), a relação entre análise e performance continua tendendo fortemente à via de mão única, sendo atribuída à performance a responsabilidade de reproduzir o achado analítico revelado pelo teórico. Este ideal pode ser percebido, por exemplo, no estudo de Beach (1987, p.157), que reconheceu no procedimento analítico a possibilidade de favorecer uma performance convincente e uma "precisa projeção de uma rede complexa dos relacionamentos contidos em sua estrutura". Larson (1983, p.31), por sua vez, atribuiu ao performer a tarefa de comunicar uma mensagem analítica da estrutura por meio da internalização do conteúdo de seus gráficos analíticos de durações reducionais ${ }^{3837}$ (LARSON, 1983, p.45). O conteúdo imperativo dessas narrativas espelha o tom imperativo e o caráter prescritivo presente em muitas das narrativas analíticas de Schenker (2005 [1924], p.62, 2005 [1924], p.112), em expressões como "prepare", "toque", "ataque" (BURKHART, 1994), "precisa" e "não precisa" (BEACH, 1987, p.166; LARSON, 1983, p.31).

Contudo, este caráter hegemônico deve ser interpretado com cautela. A observação de Rothstein (1990, p.198) sobre a suavização de estudos com conteúdo schenkeriano, tratada ao longo deste artigo, pode ser aplicada em parte dos estudos aqui mencionados. Como exemplo, podemos citar o estudo de Schachter (2000, p.48), que reconheceu a existência de alternativas interpretativas, igualmente válidas, diferentes de sua concepção analítica. A mesma ideia pode ser reconhecida em Burkhart (1983, p.112), que atentou para a diversidade interpretativa que pode ser gerada por uma mesma obra musical ou "particulares meios de execução" de aspectos diversos (dinâmica, articulação e cor).

Atualmente, essa concepção flexível pode ser tida como fonte de significações musicais diversas (COOK, 2013), estudadas como uma confluência e um resultado de vários tipos e modos de conhecimentos (LABOISSIĖRE, 2007; RINK, 2004). O distanciamento temporal nos permite desvincular a proposta analítica de Schenker do posicionamento político adotado por ele na sociedade em que estava inserido e selecionar os aspectos afeitos a construções interpretativas e expressivas de obras que respondam aos estímulos por ele propostos. Várias dentre as estratégias adotadas por Schenker e por teóricos neoschenkerianos são moldáveis a outras estratégias, mais subjetivas, e a outros repertórios, menos tonais, e podem ainda hoje fundamentar decisões de performers, sem que isso signifique uma prescrição. 


\section{Referências bibliográficas}

BEACH, David (ed.). Aspects of Schenkerian Theory. New Haven: Yale University Press, 1983.

BEACH, David (ed.). The First Movement of Mozart's Piano Sonata in A Minor, K. 310:

Some Thoughts on Structure And Performance. Journal of Musicological Research, v.7, n. 2-3, p. 157-186, 1987. Disponível em: https://doi.org/10.1080/01411898708574583. Acesso em: 31 mar. 2018.

BEACH, David (ed.). An Analysis of Schubert's "Der Neugierige": a Tribute to Greta Kraus. Canadian University Review, v. 1, n. 19, p. 69-80, 1998. Disponível em: https:// id.erudit.org/ideru dit/1014606. Acesso em: 19 fev. 2018.

BEARD, David; GLOAG, Kenneth. Musicology: the Key Concepts. New York: Routledge, 2005.

BEETHOVEN, Ludwig. Sonata Op. 2 n. 1. Piano. New York: Dover Publications, 1975 [1795]. p.3-19. 1 partitura. Disponível em: https://imslp.org/wiki/Piano_Sonata_No.1,_ Op.2_No.1_(Beethoven,_Ludwig_van). Acesso em: 8 set. 2020.

BEETHOVEN, Ludwig. Sonata Op. 57 n. 23. Piano. New York: Dover Publications, 1975 [1804-1806]. p.415-443. 1 partitura. Disponível em: https://imslp.org/wiki/Piano_ Sonata_No.23\%2C_Op.57_(Beethoven\%2C_Ludwig_van). Acesso em: 8 set. 2020.

BERRY, Wallace. Musical Structure and Performance. New Haven: Yale University Press, 1989.

BRAHMS, Johannes. Variações e fuga sobre um tema de Händel Op. 24. Piano. Leipzig: Breitkopf \& Härtel, 1927 [1862]. p.1-22. 1 partitura. Disponível em: https:// imslp.org/wiki/Variations_and_Fugue_on_a_Theme_by_Handel,_Op.24_(Brahms,_ Johannes). Acesso em: 8 set. 2020.

BURKHART, Charles. Schenker's Theory of Levels and Musical Performance. In: BEACH, David (ed.). Aspects of Schenkerian Theory. New Haven: Yale University Press, 1983. p. 95-112.

BURKHART, Charles. Mid-bar Donwbeat in Bach's Keyboard Music. Journal of Music Theory Pedagogy, v. 8, p. 3-26, 1994.

CADWALLADER, Allen; GAGNÉ, Clayton. Analysis of Tonal Music: a Schenkerian Approach. 3. ed. Oxford: Oxford University Press, 2011. 
CHEW, Geoffrey. Articulation and Phrasing. Grove Music Online, 2001. Disponível em: https://doi.org/10.1093/gmo/9781561592630.article.40952. Acesso em: 8 out. 2020.

CONE, Edward. Musical Form and Performance. New York: W. W. Norton, 1968.

COOK, Nicholas. Analysing Performance and Performing Analysis. In: COOK, Nicholas; EVERIST, Mark (ed.). Rethinking Music. New York: Oxford University Press, 1999a. p. 239-261.

COOK, Nicholas. Words about Music, or Analysis versus Performance. In: COOK, Nicholas; JOHNSON, Peter; ZENDER, Hans (ed.). Theory onto Practice: Composition, Performance and the Listening Experience. Leuven: Leuven University Press, 1999b. p. 9-52.

COOK, Nicholas. The Schenker Project: Culture, Race, and Music Theory in Fin-deSiècle Vienna. New York: Oxford University Press, 2007.

COOK, Nicholas. Beyond the Score: Music as Performance. New York: Oxford University Press, 2013.

DUNSBY, Jonathan. Execução e Análise Musical. Opus 1, Porto Alegre, v. 1, p. 6-23, 1989. Disponível em: https://www.anppom.com.br/revista/index.php/opus/article/ view/view/2/6. Acesso em: 22 jul. 2020.

FORTE, Allen; GILBERT, Steven E. Melodic Diminutions. In: FORTE, Allen; GILBERT, Steven E. Introduction to Schenkerian Analysis. New York: W. W. Norton, 1982. p. 8-82.

FRAGA, Orlando. Progressão linear: uma breve introdução à teoria de Schenker. Curitiba: DeArtes, UFPR, 2009.

GERLING, Cristina Capparelli; BARROS, Guilherme Sauerbronn de. Glossário de termos schenkerianos. Salvador: Tema, 2020.

HOOD, Alison. Interpreting Chopin: Analysis and Performance. New York: Routledge, 2014.

KERMAN, Joseph. Analysis, Theory, and New Music. In: KERMAN, Joseph.

Contemplating Music: Challenges to Musicology. Cambridge: Harvard University Press, 1985. p. 60-112.

KERMAN, Joseph. Musicologia. Trad. Álvaro Cabral. São Paulo: Martins Fontes, 1987. 
LABOISSIĖRE, Marília. Interpretação musical: a dimensão recriadora da "comunicação" poética. São Paulo: Annablume, 2007.

LARSON, Steve. On Analysis and Performance: the Contribution of Durational Reduction to the Performance of J. S. Bach's Two-part Invention in C major. Theory Only, v. 7, n. 1, p. 31-45, 1983.

MENDELSSOHN, Felix. Canções sem Palavras Op. 19 n. 1. Piano. Leipzig: Breitkopf \& Härtel, 1877 [1829-1845]. p. 1-3. 1 partitura. Disponível em: https://imslp.org/wiki/ Lieder_ohne_Worte_(Mendelssohn\%2C_Felix). Acesso em: 10 set. 2020.

MORGAN, Robert P. Becoming Heinrich Schenker: Music Theory and Ideology. Cambridge: Cambridge University Press, 2014.

MOZART, Wolfgang Amadeus. Sonata K. 310/300. Piano. Leipzig: Breitkopf \& Härtel, 1878 [1778]. 1 partitura. Disponível em: https://imslp.org/wiki/Piano_Sonata_No.8_ in_A_minor,_K.310/300d_(Mozart,_Wolfgang_Amadeus). Acesso em: 4 mar. 2021.

RINK, John. The State of Play in Performance Studies. In: DAVIDSON, Jane W (ed.). The Music Practitioner: Research for the Music Performer, Teacher and Listener. Burlington: Ashgate Publishing, 2004. p. 37-51.

ROTHSTEIN, William. Heinrich Schenker as an Interpreter of Beethoven's Piano Sonatas. 19th-Century Music, v. 8, n. 1, p. 3-28, 1984. Disponível em: https://www. jstor.org/stable/ 746247. Acesso em: 15 ago. 2018.

ROTHSTEIN, William. The Americanization of Heinrich Schenker. In: SIEGEL, Hedi (ed.). Schenker Studies. New York: Cambridge University Press, 1990. p. 193-203.

SCHACHTER, Carl. 20th-Century Analysis and Mozart Performance. Early Music, v. 19, n. 4, p. 620-626, 1991. Disponível em: http://www.jstor.org/stable/3127925. Acesso em: 5 fev. 2018.

SCHACHTER, Carl. Chopin's Prelude in D Major, Op. 28, No. 5: Analysis and Performance. Journal of Music Theory Pedagogy, n. 8, p. 27-45, 1994.

SCHACHTER, Carl. Playing What the Composer Didn't Write: Analysis and Rhythmic Aspects of Performance. In: BRUBAKER, Bruce; GOTTLIED, Jane. Pianist, Scholar, Connoisseur: Essays in Honor of Jacob Lateiner. New York: Pendragon Press, 2000. p. 47-68.

SCHACHTER, Carl. Elephants, Crocodiles, and Beethoven: Schenker's Politics and the 
Pedagogy of Schenkerian Analysis. Theory and Practice, v. 26, p. 1-20, 2001. Disponível em: https: jstor.org/stable/41054326. Acesso em: 14 jan. 2018.

SCHENKER, Heinrich. Free Composition (Der freie Satz). Trad. Ernst Oster. New York: Longman, 1979 [1935].

SCHENKER, Heinrich. The Art of Performance. Editado por Heribert Esser. Trad. Irene Schreier Scott. New York: Oxford University Press, 2000.

SCHENKER, Heinrich. Der Tonwille: Pamphlets/Quartely Publication in Witness of the Immutable Laws of Music, Offered to a New Generation of Youth. Editado por William Drabkin. Trad. Ian Bent et al. New York: Oxford University Press, 2004 [1921-1923]. v. 1, n. $1-5$.

SCHENKER, Heinrich. Der Tonwille: Pamphlets/Quartely Publication in Witness of the Immutable Laws of Music, Offered to a New Generation of Youth. Editado por William Drabkin. Trad. Ian Bent et al. New York: Oxford University Press, 2005 [1923-1924]. v. 2, n. 6-10.

SCHENKER, Heinrich. The Masterwork in Music. Editado por William Drabkin. Trad. Ian Bent et al. New York: Dover Publications, 2014a [1925]. V. 1.

SCHENKER, Heinrich. The Masterwork in Music. Editado por William Drabkin. Trad. Ian Bent et al. New York: Dover Publications, 2014b [1926]. V. 2.

SCHMALFELDT, Janet. In the Process of Becoming: Analytical and Philosophical Perspectives on Form in Early Nineteenth-Century Music. Oxford: Oxford University Press, 2011.

SWINKIN, Jeffrey. Performative Analysis: Reimagining Music Theory for Performance. New York: University of Rochester Press, 2016. 